\title{
A relevância da informação contábil na identificação de empresas criadoras de valor: um estudo do setor de energia elétrica brasileiro
}

The relevance of accounting information in the identification of value creating companies: a study of the brazilian electricity sector

\section{Ana Carolina Costa Corrêa}

Doutoranda em Administração pela Faculdade de Administração, Economia e Contabilidade da Universidade de São Paulo, campus Ribeirão Preto Endereço: Avenida dos Bandeirantes, 3900, Monte Alegre

CEP: 14040-905 - Ribeirão Preto/SP - Brasil

E-mail: carolcorrea@yahoo.com

Telefone: (16) 3602-4746

\section{Alexandre Assaf Neto}

Doutor em Administração pela Universidade de São Paulo.

Professor Titular do Departamento de Contabilidade da Faculdade de Administração,

Economia e Contabilidade da Universidade de São Paulo, campus Ribeirão Preto (FEA-

RP/USP).

Endereço: Avenida dos Bandeirantes, no 3900, Monte Alegre

CEP: 14040-905 - Ribeirão Preto/SP- Brasil

E-mail: assaf@terra.com.br

Telefone: (16) 3602-4746

\section{Sílvio Hiroshi Nakao}

Doutor em Controladoria e Contabilidade pela Universidade de São Paulo

Professor do Programa de Pós-Graduação em Controladoria e Contabilidade da FEA-RP/USP

Endereço: Av. Bandeirantes, 3900, Monte Alegre

CEP: 14040-030 - Ribeirão Preto/SP - Brasil

E-mail: shnakao@usp.br

Telefone: (16) 3602-4746

\section{Alyne Anteveli Osajima}

Mestre em Ciências pela Universidade de São Paulo

Endereço: Rua T064, Quadra 149, Lote 9/11, Apto 603 R, Bairro: Setor Bueno

CEP: 74230-110 - Goiânia/GO -Brasil

E-mail: lyosajima@yahoo.com.br

Telefone: (62) 8122-6060

Artigo recebido em 14/06/2011. Revisado por pares em 07/09/2012. Reformulado em 07/11/2012. Recomendado para publicação em 22/11/2012 por Sandra Rolim Ensslin (Editora Científica). Publicado em 14/12/2012. 


\title{
Resumo
}

A relevância da informação contábil é um dos princípios que norteia a Contabilidade. Sabendo-se que a criação de valor é um dos principais objetivos da empresa, este trabalho buscou identificar os indicadores contábeis mais relevantes para discriminar as companhias criadoras de valor no setor de energia elétrica brasileiro. Foi utilizada uma amostra de 52 empresas com ações negociadas na BM\&FBOVESPA, totalizando 385 balanços anuais. Os resultados indicam que houve geração de valor em $41,82 \%$ dos casos. Além disso, apontam quatro indicadores como mais relevantes: retorno sobre o patrimônio líquido, composição do endividamento bancário, independência financeira e composição do endividamento.

Palavras-chave: Relevância da informação contábil. Valor econômico agregado (VEA). Indicadores contábeis. Gestão baseada no valor.

\begin{abstract}
The relevance of accounting information is one of the accounting guiding principles. Knowing that value creation is one of the main objectives of the company, this study sought to identify the most relevant financial indicators for discriminating companies that create value in the Brazilian electricity sector. We used a sample of 52 companies listed on the BM\&FBOVESPA, totaling 385 annual statements. The results indicate that there was value generation in $41.82 \%$ of cases. In addition, they point four indicators as most relevant: return on equity, bank debt composition, financial independence and composition of debt.
\end{abstract}

Keywords: Relevance of accounting information. Economic value added (EVA). Accounting indicators. Value-based management.

\section{Introdução}

Cada vez mais as informações contábeis estão voltadas para auxiliar a tomada de decisão dos usuários externos, especialmente investidores. Isso pode ser visto explicitamente no Pronunciamento Conceitual Básico do Comitê de Pronunciamentos Contábeis (CPC), que destaca a relevância como uma das quatro principais características qualitativas das demonstrações contábeis. Nesse contexto, está a literatura sobre a relevância da informação contábil, conhecida como Value-Relevance, na qual muitas pesquisas foram desenvolvidas relacionando as informações contábeis e o mercado de capitais, testando sua capacidade de influenciar a tomada de decisões dos investidores.

Um dos principais interesses destes é avaliar as empresas, tanto para escolher em qual investir, como para verificar se o resultado está dentro do esperado. Há diversas medidas de desempenho que podem ser usadas para essa finalidade. Porém, a Moderna Teoria Financeira defende que a administração está voltada para a criação de riqueza, e a orientação básica das decisões financeiras das empresas segue o objetivo principal de maximização da riqueza de seus proprietários (ASSAF NETO, 2010). 
Nesse contexto, encontra-se a Gestão Baseada no Valor (Value Based Management VBM), que fornece aos gestores uma métrica precisa e não ambígua sob a qual toda a organização deve ser criada, que é a geração de valor (KOLLER, 1994).

Dentre as medidas de criação de valor, destaca-se o VEA (Valor Econômico Agregado), muito utilizado tanto no mercado quanto na academia. É uma medida de criação de valor relacionada ao desempenho operacional da própria empresa. Ele pode ser descrito como o lucro econômico, ou seja, o resultado apurado que excede à remuneração mínima exigida pelos proprietários de capital (KOLLER; GOEDHART; WESSELS, 2005).

Segundo Copeland, Koller e Murrin (2002), no mercado real, a regra para tomada de decisões é a escolha de estratégias que maximizem o lucro econômico. Essa consciência levou um número crescente de administradores a se concentrar na criação de valor e, consequentemente, na identificação de quais fatores levam à sua criação.

As principais variáveis que influenciam a geração de valor são os chamados direcionadores de valor, ou seja, uma alteração em um deles tem a capacidade de alterar o valor final de uma empresa (RAPAPPORT, 2001).

Dessa forma, considerando-se que a Contabilidade é a principal fornecedora de informações para os investidores e que para estes interessa a identificação de empresas geradoras de valor, pode-se destacar um importante ponto de investigação: identificar como as informações contábeis publicadas podem ser relacionadas à geração de valor, usada como medida de desempenho.

Assim, este trabalho teve como questão de pesquisa: Quais são os indicadores contábeis mais relevantes para discriminar empresas criadoras de valor no setor de energia elétrica do mercado de capitais brasileiro?

Ao testar quais indicadores contábeis estão mais associados à criação de valor ao acionista, este trabalho teve como objetivo principal avaliar a relevância da informação contábil na identificação de companhias do setor elétrico criadoras de valor no mercado de capitais brasileiro. A escolha desse setor é justificada pela sua importância econômica para o País. Segundo Pereira et al. (2008), a energia elétrica é fundamental para o desenvolvimento social e econômico de uma região, por ser um dos mais importantes componentes da rede de infraestrutura, atuando como um insumo básico de vários setores da atividade econômica. Blacconiere, Johnson e Johnson (2000) também ressaltam a importância de estudar esse setor devido à maior atenção que tem recebido pelos investidores, principalmente em relação à relevância dos lucros e valores contábeis na avaliação da firma. Além disso, como pode ser observado na Tabela 1, no período em análise (de 2000 a 2009), ele representava $12 \%$, em média do valor de mercado das companhias de capital aberto não financeiras listadas na BM\&FBOVESPA e correspondia a $88,5 \%$ do setor de utilidade pública.

Tabela 1 - Representatividade do setor de energia elétrica no mercado brasileiro

\begin{tabular}{lr}
\hline & Média do Valor de Mercado* \\
\hline Total não financeiro & $\mathrm{R} \$ 959.101 .838 .641,77$ \\
Setor de energia elétrica & $\mathrm{R} \$ 114.253 .225 .336,62$ \\
Representação do setor de energia elétrica em relação ao total não financeiro & $11,9 \%$ \\
Setor de utilidade pública & $\mathrm{R} \$ 129.085 .025 .030,24$ \\
Representação do setor de energia elétrica em relação ao setor de utilidade pública & $88,5 \%$ \\
\hline
\end{tabular}

*Média dos valores de dezembro de cada ano entre 2001 e 2009.

Fonte: BM\&FBOVESPA (2012). 
Com esse objetivo, foram identificados quais indicadores contábeis melhor discriminam as empresas criadoras das destruidoras de valor com ações negociadas na BM\&FBOVESPA do setor de energia elétrica no Brasil. Essa análise empírica contou com a aplicação das técnicas de regressão logística, teste $t$ e correlação numa amostra de 52 empresas de capital aberto, no período de 2000 a 2009, totalizando 385 dados de Balanços Anuais. Para isso, foram utilizados 24 indicadores financeiros de forma a refletir as principais estratégias da empresa ligadas à estrutura de capital, rentabilidade, liquidez, operação e investimento.

Diante desse cenário, este trabalho preenche uma lacuna do conhecimento ao fornecer uma discussão sobre a relevância das informações contábeis publicadas nos demonstrativos financeiros para os investidores, focados principalmente na busca de empresas geradoras de valor.

Além disso, há uma grande importância econômica na identificação das empresas que geram valor do ponto de vista do usuário externo. Assim, a pesquisa é relevante também aos analistas e gestores de investimentos, para melhor orientação de suas decisões e incentivo a uma avaliação mais racional dos papéis e composição de suas carteiras. A principal razão é que, com a identificação dos principais direcionadores de valor, eles terão melhores argumentos para avaliar as decisões dos gestores e selecionar as empresas que apresentam maior potencial de geração de valor no longo prazo, por meio de informações publicadas.

Como contribuição adicional, pretende-se colaborar com os gestores de empresas de capital aberto desse setor, fornecendo-lhes subsídios para melhor tomada de decisão dentro da gestão baseada no valor. Isso acontece porque eles poderão definir as estratégias da empresa de acordo com o impacto que elas terão nos indicadores identificados (principais direcionadores de valor) ou usá-los para avaliação de desempenho dos colaboradores e estabelecimento de metas.

O desenvolvimento do artigo apresenta-se dividido em cinco partes. A primeira inclui esta introdução; a segunda é o referencial teórico, que discute a relevância da informação contábil e a gestão baseada no valor; a terceira trata de aspectos metodológicos; a quarta demonstra os resultados apurados; e, por fim, são apresentadas as conclusões da pesquisa.

\section{Referencial Teórico}

\subsection{Relevância da informação contábil}

Collins, Maydew e Weiss (1997) relatam que estudos do Value-Relevance geralmente examinam o poder do lucro contábil e o valor contábil do patrimônio para explicar o preço das ações. Corroborando com a mesma ideia, Sami e Zhou (2004) entendem que a relevância da informação contábil é a capacidade de os números contábeis resumir a informação baseada no preço das ações.

Na literatura contábil-financeira, há vários estudos sobre o Value-Relevance. Neles, as variáveis contábeis são utilizadas para avaliar o preço e o retorno das empresas, exercendo seus poderes explanatórios na geração de valor. Dimitropoulos e Asteriou (2009), Song, Thomas e Yi (2010) e Chalmers, Navissi e Qu (2010) são exemplos de estudiosos que demonstram a relevância das demonstrações financeiras.

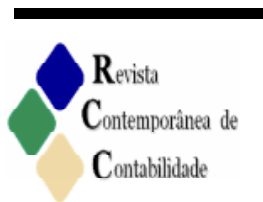

ISSN 2175-8069, UFSC, Florianópolis, v.9, n.18, p.137-166, jul./dez., 2012 
Ressalta-se que grande parte dessa literatura focou seu trabalho em países desenvolvidos para avaliar a relevância dos resultados contábeis, como, por exemplo, o trabalho de Collins e Kothari (1989). Isso ocorreu, pois, inicialmente, havia um receio quanto aos países em desenvolvimento, quanto à sua baixa relevância das informações contábeis para analisar o mercado de capitais. Entretanto, essa ideia foi sendo superada com a realização de pesquisas e comprovação de resultados. Análises empíricas encontraram que a informação é impactada pelo ambiente em que atua, inclusive nos países subdesenvolvidos (ALALI; FOOTE, 2012; AL-HARES; ABUGHAZALEH; HADDAD, 2012; ALI; HWANG, 2000; CHALMERS; NAVISSI; QU, 2010; CHEN; CHEN; SU, 2001; EBAID, 2011; TSALAVOUTAS; ANDRÉ; EVANS, 2012).

Ali e Hwang (2000) realizaram um estudo comparativo de 16 países com os Estados Unidos. Observaram que a relevância da informação contábil é influenciada por diversos fatores, tais como o continente do país, as regras tributárias, as baixas despesas com os serviços de auditoria externa, a inflação, entre outros. Em outras palavras, a análise do valor relevante também leva em consideração o ambiente em que as empresas estão inseridas. Nessa seara, a pesquisa empírica de Chalmers, Navissi e Qu (2010) apresenta evidências da relevância da informação contábil em um mercado emergente: a China. Chen, Chen e Su (2001) encontraram os mesmos resultados nesse ambiente, ou seja, evidências de que a informação contábil é relevante para os investidores. Dimitropoulos e Asteriou (2009) também se encaixam nesses exemplos ao testarem a relevância das informações financeiras dentro do contexto de um mercado de capitais emergentes, como a Grécia. Realizado no mesmo mercado, o estudo recente de Tsalavoutas, André e Evans (2012) avaliou a relevância da informação contábil antes e depois da adoção do International Financial Reporting Standards (IFRS) na Grécia. Alali e Foote (2012) também avaliaram a relevância da informação contábil sob as normas internacionais de Contabilidade (IFRS) na Bolsa de Valores de Abu Dhabi (ADX). Atualmente, há também estudos sobre a relevância da informação contábil em outros mercados como a pesquisa de Al-Hares, Abu Ghazaleh e Haddad (2012), no Kuwait; Srinivasan e Narasimhan (2012), na Índia; e de Ebaid (2011), no Egito. Este último merece destaque, pois avaliou a relevância de medidas de desempenho baseada na contabilidade em mercados emergentes, assim como o presente estudo.

Dentre os mercados emergentes, também foram realizadas pesquisas empíricas no Brasil. Por exemplo, o estudo de Murcia et al. (2008) faz uma discussão sobre a adoção de medidas baseadas no valor justo, avaliando a relevância da informação contábil. No mesmo mercado, Helou Netto e Pereira (2010) investigaram se a republicação de demonstrações financeiras impactava o preço das ações. Jacques et al. (2011), em um estudo mais recente, avaliaram a relevância das informações contábeis para o atendimento de normas de governança corporativa.

Nesse ínterim, destaca-se uma importante literatura, citada por muitos como precursora: é a de Ball e Brown (1968). Eles foram os primeiros a destacar a relação entre os preços das ações e as informações divulgadas nas demonstrações financeiras. Relacionaram a informação contábil e o mercado de capitais. Concluíram que o lucro tem um valor informativo, constatando que nem toda informação é antecipada apenas pelo mercado, havendo uma tendência após a divulgação dos relatórios contábeis. Kothari (2001) demonstra essa importância ao informar que, num período de três décadas, foram mais de mil artigos publicados. 
No campo da pesquisa empírica sobre o Value-Relevance, sua raiz está na teoria sobre os modelos de avaliação patrimonial. Os estudos de Ohlson (1995) fornecem uma base conceitual sobre o poder explanatório das variáveis. Fundamentam que os números contábeis fornecem suporte para a análise da avaliação econômica da empresa, criando seu modelo para examinar a relação entre o valor de mercado e os valores contábeis reconhecidos e divulgados. Em outras palavras, o valor de uma empresa pode ser expresso como uma função linear do valor contábil, do lucro e de outros valores relevantes da informação.

Essa trajetória evidencia que a Contabilidade tornou-se indispensável para os usuários terem condições de avaliar as empresas e realizar seus investimentos. Por meio de seus demonstrativos, índices contábeis e variáveis, ela gera informações relevantes para a tomada de decisões. Este é um dos motivos que justifica o interesse de pesquisadores na literatura do Value-Relevance.

Assim, como a informação contábil está no rol dos principais meios de comunicação entre a empresa e seus usuários, cada vez mais a Contabilidade busca melhorar o nível de transparência em seus relatórios. No Brasil, isso pode ser visto na adoção das normas internacionais de Contabilidade (IFRS), sendo que, no Pronunciamento Conceitual Básico, emitido pelo Comitê de Pronunciamentos Contábeis (CPC), a relevância é destacada como uma das quatro características qualitativas das demonstrações contábeis. Eles citam que "para serem úteis, as informações devem ser relevantes às necessidades dos usuários na tomada de decisões" (COMITÊ DE PRONUNCIAMENTOS CONTÁBEIS, 2008, p. 11).

No mesmo pronunciamento, eles explicam que "as informações são relevantes quando podem influenciar as decisões econômicas dos usuários, ajudando-os a avaliar o impacto de eventos passados, presentes ou futuros ou confirmando ou corrigindo as suas avaliações anteriores" (COMITÊ DE PRONUNCIAMENTOS CONTÁBEIS, 2008, p. 11).

É nesse cenário que este artigo se insere, ou seja, na avaliação de quais informações contábeis são mais relevantes para avaliação de desempenho de empresas dentro da gestão baseada no valor, que na teoria moderna de finanças pode ser considerada uma das principais decisões econômicas dos usuários.

\subsection{Gestão baseada no valor}

Segundo Porterfield (1976), para que as decisões sejam tomadas em uma base racional dentro das empresas é preciso que haja um objetivo, pois, sem ele, não haverá um critério pelo qual medir o efeito das decisões propostas. A Teoria dos Shareholders defende que a empresa deveria maximizar o bem-estar econômico de seus proprietários como objetivo principal. Baseada nessa teoria, surge a gestão baseada no valor, que nada mais é do que gerir a empresa de acordo com o objetivo de maximização de riqueza dos acionistas, ou seja, gerar valor (DAMODARAN, 1997).

Nesse contexto, é preciso, primeiro, definir uma forma de mensurar a geração de valor. Grant (2003) destaca que, diferente do lucro contábil, a relação entre o lucro econômico e a geração de valor para o acionista é transparente. Isso ocorre, pois a medida de maximização do lucro líquido, comumente usada, não leva em consideração o risco inerente à atividade da empresa, ou seja, não considera os riscos associados aos fluxos esperados de rendimentos (MARTINS, 2009). Essa lacuna pode ser preenchida pelo Valor Econômico Agregado (VEA), que é o resultado contábil apurado que excede à remuneração mínima exigida pelos proprietários de capital (credores e acionistas).

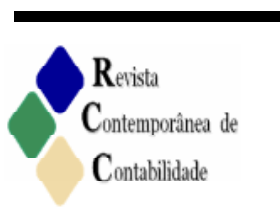

ISSN 2175-8069, UFSC, Florianópolis, v.9, n.18, p.137-166, jul./dez., 2012 
De acordo com Assaf Neto (2003), o conceito da medida de valor econômico agregado é bastante antigo, sendo conhecido na literatura contábil e financeira por lucro residual ou lucro econômico. Ele data, pelo menos, de 1890, pois consta no trabalho do economista Alfred Marshall (1890, v. 1, p. 142 apud COPELAND; KOLLER; MURRIN, 2002, p. 147) que "o valor criado por uma empresa durante qualquer período de tempo (seu lucro econômico) deve levar em consideração não somente as despesas lançadas em seus registros contábeis, mas, também, o custo de oportunidade do capital utilizado na empresa". Posteriormente, sua popularização deu-se com a denominação de Economic Value Added $\left(E^{\circledR}{ }^{\circledR}\right)$, marca registrada de propriedade da Stern Stewart \& Co (GRANT, 2003). Assim, neste trabalho foram considerados sinônimos os termos VEA, EVA ${ }^{\circledR}$, lucro econômico e lucro residual, usados como proxy para criação de valor, medida de desempenho empresarial na gestão baseada no valor.

Dentro desta teoria, é de suma importância identificar quais são as estratégias e ações que levam à geração de valor. Koller, Goedhart e Wessels (2005, p. 410) definem direcionador de valor (value driver) como "uma ação que afeta o desempenho de um negócio no curto ou no longo prazo e assim cria valor" (Tradução nossa).

Segundo Bloxham (2003), entender os maiores direcionadores da criação de valor é uma questão de causalidade, uma questão que envolve real persistência, hipotetização e teste para discernimento. É uma questão-chave para as organizações. Frezatti (2003) confirma essa visão ao dizer que as decisões da empresa devem ser tomadas de acordo com sua capacidade de geração futura de caixa, pois, antever o valor esperado da empresa no futuro, é uma valiosa etapa do processo decisório das empresas dentro da gestão baseada no valor.

Em busca de uma classificação que gerasse melhor entendimento dos direcionadores de valor, Assaf Neto (2010, p. 155) dividiu-os em estratégias financeiras e capacidades diferenciadoras. Essas últimas "são entendidas como estratégias adotadas que permitem às empresas atuarem com um nível de diferenciação em relação a seus concorrentes de mercado, assumindo uma vantagem competitiva e maior agregação de mercado a seus proprietários". Elas podem ser classificadas em relações de negócios, conhecimento do negócio, qualidade e inovação. Por outro lado, as estratégias financeiras refletem as capacidades diferenciadoras e podem ser identificadas nos demonstrativos financeiros das empresas. Por exemplo, um aumento no giro dos estoques é consequência de uma menor necessidade de investimentos em giro, promovendo um maior retorno aos proprietários e maior valor agregado.

Rapapport (2001) apresentou outra classificação: os microdirecionadores e os macrodirecionadores de valor. Estes são de natureza financeira e influenciados pelos microdirecionadores, que, por sua vez, correspondem aos resultados de natureza operacional, ou seja, viabilizam os resultados estratégicos da organização.

Assim, como os indicadores financeiros (macrodirecionadores de valor), calculados a partir dos demonstrativos contábeis, refletem as estratégias da empresa (microdirecionadores de valor) e por este trabalho ter como objetivo avaliar a relevância da informação contábil na geração de valor, verificou-se como esses indicadores estão relacionados ao VEA.

Ao escolher quais indicadores usar, buscou-se os mais citados dentro da literatura de análise de balanços que refletissem as principais estratégias das empresas que poderiam estar, de alguma forma, relacionadas à geração de valor, divididas em estrutura de capital, rentabilidade, liquidez, operação e investimento.

Para elevar seu valor, a empresa precisa fazer uma ou mais dentre as seguintes medidas (COPELAND; KOLLER; MURRIN, 2002, p.146): 


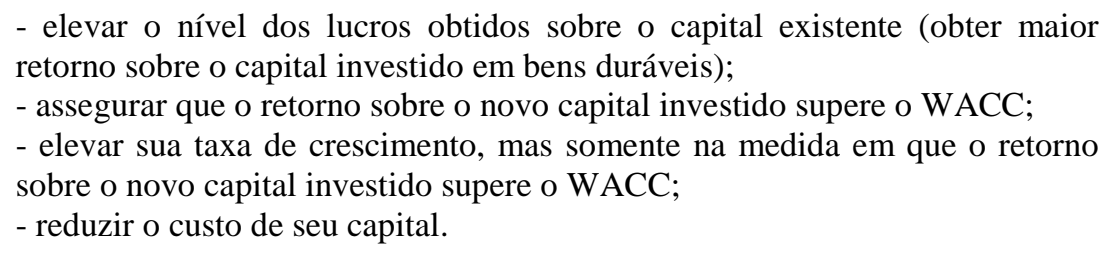

Dessa forma, a rentabilidade pode ser relacionada de forma positiva à geração de valor, pois está associada a um aumento no nível dos lucros obtidos pela empresa em relação ao capital existente. Já a liquidez representa a saúde financeira da empresa e, apesar de não estar diretamente relacionada à criação de valor, pode haver uma relação indireta com esta por sua influência nos riscos da empresa, impactando seu custo de capital (KOLLER; GOEDHART; WESSELS, 2005). Além disso, a decisão do gestor sobre a escolha do nível de liquidez pode influenciar sua decisão de investimento quando o capital disponível for restrito.

Em relação à estrutura de capital, inicialmente Modigliani e Miller (1958) destacaram, em sua proposição I, a irrelevância da proporção de capital próprio e de terceiros na captação de recursos para o valor de uma firma, considerando a ausência de impostos, custos de transação e imperfeições de mercado. No mesmo trabalho, ao incluir a existência de impostos, estabeleceram a proposição II que cita o aumento do valor da empresa por meio da alavancagem financeira. Diversas pesquisas sobre o tema foram desenvolvidas desde então, e, apesar de não haver um resultado conclusivo, é consenso na literatura de estrutura de capital que ela pode exercer alguma influência no valor da companhia, pois afeta o seu custo de capital por meio da alavancagem financeira. Segundo Magni (2005), não há um modelo claro para encontrar a estrutura ótima de capital, ou seja, o grau de alavancagem que gera o maior valor possível aos acionistas, mas há evidências de que a alavancagem traz benefícios assim como aumenta certos custos. Koller, Goedhart e Wessels (2005) destacam que os principais fatores a serem considerados são: economia de impostos, redução do sobreinvestimento corporativo, custos de falência e de decadência do negócio e custos de conflitos entre investidores.

As estratégias de investimento podem influenciar a geração de valor à medida que estão relacionadas à busca eficiente de novas oportunidades de mercado criadoras de valor, à redução dos investimentos sem alteração do volume de atividade e à identificação de ativos destruidores de valor, ou seja, que não conseguem um retorno suficiente para remunerar o custo do capital empregado. Por outro lado, as estratégias operacionais podem ser consideradas direcionadoras de valor quando a empresa busca maximizar a eficiência das decisões operacionais, estabelecendo políticas de preços, de compras, de vendas e de estoques voltadas a criar valor (ASSAF NETO, 2010).

Hall (1999) destacou 18 variáveis econômico-financeiras como direcionadoras de valor: retorno sobre o capital empregado, margem operacional de vendas após impostos, margem operacional do capital investido após impostos, margem operacional antes dos impostos, margem bruta, crescimento das vendas, lucro retido/capital investido, vendas/capital investido, vendas/capital circulante líquido, vendas/ativo fixo, WACC (Weighted Average Cost of Capital - Custo Médio Ponderado de Capital), empréstimos de longo prazo/capital investido, capital de terceiros de longo prazo/capital investido, mudanças em capital investido/ NOPAT (Net Operating Profit After Taxes - Lucro Operacional), alíquota de impostos, alavancagem operacional, alavancagem financeira. 
Assaf Neto (2010) dividiu as estratégias financeiras em três blocos: operacionais, financiamento e investimento. Os direcionadores de valor das estratégias financeiras operacionais são: crescimento das vendas, prazos operacionais de cobrança e pagamento, giro dos estoques e margem de lucro. Já as de financiamento contam com os seguintes direcionadores de valor: estrutura de capital, custo do capital próprio, custo do capital de terceiros e risco financeiro. Por fim, os direcionadores das estratégias financeiras de investimento são: investimento em capital de giro, investimento em capital fixo, oportunidades de investimentos, análise giro x margem e risco operacional.

Para Young e O'Byrne (2003), eles correspondem a cinco principais: giro dos ativos fixos, prazo de estocagem, prazo de recebimento das contas a receber, prazo de pagamento das contas a pagar e índice de conversão em caixa. Moskowitz (1988) e Stewart (1991) encontraram seis: NOPAT, benefício fiscal associado à dívida, montante de novo capital investido, taxa de retorno sobre o novo capital investido, custo de capital da empresa e tempo de duração do crescimento em valor. Martin e Petty (2004), por sua vez, identificaram outros seis: crescimento de vendas, margem de lucro operacional, alíquota de imposto de renda base caixa, capital de giro líquido/vendas, ativos fixos/vendas e outros ativos de longo prazo/vendas.

Nesse contexto, há também diversos trabalhos empíricos que trataram desse tema. Por exemplo, o estudo de Fiordelisi e Molyneux (2010) teve como objetivo descobrir os determinantes da geração de valor para os acionistas de bancos europeus. O trabalho de Trémolières e Turko (2009) avaliou se as fusões e aquisições nas firmas de internet criavam valor na Europa e na América. O estudo de Fader e Hardie (2010) analisou como bases de clientes estavam relacionadas com a avaliação de empresas. Na pesquisa realizada por Joshi e Hanssens (2010), foram avaliados os efeitos diretos e indiretos dos gastos com publicidade no valor de empresas.

No Brasil, Araújo (2005) verificou a relação do VEA com variáveis macroeconômicas. Palma (2004) avaliou a capacidade de inovação como formadora de valor. Em outra linha de pesquisa, Pignanelli (2007) pesquisou a contribuição da gestão da qualidade para os resultados financeiros, incluindo a geração de valor. Bonizio (2005) estudou a análise de sensibilidade do valor econômico agregado dentro de cada setor da economia brasileira. Tavares Filho (2006) procurou verificar o impacto das práticas de governança corporativa no valor da firma. Outro trabalho interessante sobre o tema é o de Cabello e Parisi (2008), que analisou se as práticas de Gestão Baseada em Valor utilizadas pelas empresas são coerentes com o proposto pela teoria. Por fim, pode-se destacar o trabalho recente de Sobue e Pimenta Jr. (2012) sobre a relação entre a geração de valor econômico e o valor de mercado das empresas sucroalcooleiras brasileiras.

\section{Metodologia}

No desenvolvimento deste estudo foram coletadas as demonstrações contábeis de 52 empresas de capital aberto com ações negociadas na BMF\&BOVESPA do setor de energia elétrica do Brasil. Além disso, com base na revisão de literatura e nas teorias apresentadas, foram selecionados diversos indicadores contábeis, dentre os econômico-financeiros, que podem influenciar a geração de valor. Abaixo estão descritas as variáveis dependente e independente. A seguir, será descrita a coleta de dados e analisada a ferramenta utilizada para 
a seleção das variáveis que melhor discriminam as empresas criadoras das destruidoras de valor. Para realizar os cálculos e testes estatísticos foi utilizado o software SPSS ${ }^{\circledR}$.

\subsection{Variáveis}

\section{Variável dependente:}

Valor Econômico Agregado (VEA) = Lucro Líquido - Ke*Patrimônio Líquido (JORION, 2003, p. 557), sendo:

Lucro Líquido $=$ Resultado líquido contábil divulgado para o referido ano, incluindo a participação de acionistas minoritários, no caso de grupos de empresas. Alguns autores sugerem alguns ajustes para o cálculo do lucro a ser utilizado no VEA, como, por exemplo, a exclusão de gastos com pesquisa e desenvolvimento e receitas provenientes do excesso de liquidez (ASSAF NETO, 2010; KOLLER; GOEDHART; WESSELS, 2005; STEWART, 1991). Porém, neste trabalho estes ajustes não foram considerados pela dificuldade e principalmente pela subjetividade em fazê-los com base em dados publicados, o que não invalida a pesquisa, já que foi utilizado o ativo total, e não o investimento para o cálculo dos indicadores.

Patrimônio Líquido = Patrimônio líquido anual médio, incluindo participação de minoritários

$\mathrm{Ke}=$ custo do capital próprio, que foi calculado pelo modelo de precificação de ativos de capital (CAPM) de Sharpe (1964) e Lintner (1965). Porém, pela dificuldade de cálculo dos valores que o compõe em países emergentes, como o Brasil, optou-se por fazê-lo através de benchmarking do mercado norte-americano, onde ele é calculado como se a empresa estivesse naquele mercado e acrescenta-se o risco específico do país (KOLLER; GOEDHART; WESSELS, 2005). A fórmula usada é destacada a seguir:

$$
\mathrm{Ke}=\mathrm{Rf}+\beta^{*}(\mathrm{Rm}-\mathrm{Rf})+\text { Risco-Brasil (ASSAF NETO, 2010, p. 436) }
$$

onde:

$\mathrm{Rf}=$ taxa livre de risco (risk free) $=$ taxa média anual do T-Note de 10 anos dos Estados Unidos (COPELAND; KOLLER; MURRIN, 2002)

$\mathrm{Rm}=$ taxa de retorno do mercado $=$ taxa média de 20 anos do retorno mensal do índice da NYSE (Bolsa de Valores de Nova Iorque), escolhido pois, dentre os índices mais comuns (S\&P500, Nasdaq e Dow Jones) é o que abrange o maior número de empresas, com características diversas e usa um critério objetivo de análise.

$\beta=$ beta (medida de risco sistemático). Foi utilizado o beta médio não alavancado das empresas listadas na NYSE do setor de energia elétrica, ou seja, o beta de empresas norteamericanas com risco econômico similar, e posteriormente alavancado pela estrutura de capital de cada empresa brasileira em análise, de forma a refletir além do risco econômico, o risco financeiro específico de cada firma, utilizando a alíquota de imposto de renda brasileira. A fórmula utilizada foi:

$$
\beta=\beta_{\mathrm{u}} *[1+(\text { Passivo Oneroso/Patrimônio Líquido)*(1-IR)] (HAMADA, 1969) }
$$


$\beta_{\mathrm{u}}=$ beta médio não alavancado do setor de energia elétrica dos Estados Unidos

Passivo Oneroso = Passivo oneroso médio da empresa brasileira em análise

$\mathrm{IR}=$ alíquota de imposto de renda mais contribuição social sobre o lucro líquido $(\mathrm{CSLL})=34 \%$

\section{Variáveis independentes:}

As variáveis independentes da pesquisa foram os indicadores contábeis, usados para operacionalizar as principais estratégias empresariais, já que, segundo Assaf Neto (2010), refletem seu desempenho. Elas podem ser divididas em estrutura de capital, rentabilidade, liquidez, operação e investimento.

A escolha dos indicadores deu-se com base na literatura estudada, especialmente a relacionada à mensuração de desempenho financeiro empresarial e análise de balanços, buscando-se os que refletissem as estratégias empresariais de forma mais abrangente. Dessa maneira, no Quadro 1 estão relacionadas às variáveis independentes desta pesquisa, sendo que os códigos usados nos testes encontram-se entre parênteses, logo após seu nome, respectivamente. A alíquota de imposto de renda e a contribuição social sobre o lucro líquido utilizada foram de $34 \%$.

\section{Quadro 1 - Variáveis independentes}

\begin{tabular}{|l|}
\hline \multicolumn{1}{c|}{ Estrutura de Capital } \\
\hline 1 - Independência Financeira (IndFinanc) = Patrimônio Líquido/Ativo Total \\
2 - Índice de Endividamento Oneroso (EndOner) = Passivo Financeiro/Patrimônio Líquido \\
3 - Composição do Endividamento $($ CompEnd) $=$ Passivo Circulante/Passivo \\
4 - Composição do Endividamento Bancário $($ EndBanc) =Passivo Circulante Financeiro/ Passivo Financeiro \\
5 - Imobilização do Patrimônio Líquido (ImobPL) = Permanente/Patrimônio Líquido \\
6 - Imobilização de Recursos Não Correntes (ImobRNC) = Permanente/(Patrimônio Líquido + Passivo Não \\
Circulante) \\
\hline 7 - Retorno sobre o Ativo (ROA) = Lucro Operacional (NOPAT)/Ativo Total \\
8 - Retorno sobre o Patrimônio Líquido (ROE) = Lucro Líquido/Patrimônio Líquido \\
9 - Margem Operacional (MargOp) = Lucro Operacional (NOPAT)/Receita Líquida \\
10 - Margem Líquida (MargLiq) = Lucro Líquido/Receita Líquida \\
11 - Giro do Ativo (GiroAt) = Receita Líquida/Ativo Total \\
12 - Giro do Patrimônio Líquido (GiroPL) = Receita Líquida/Patrimônio Líquido \\
\hline
\end{tabular}

\section{Liquidez}

13 - Liquidez Corrente (LiqCorr) = Ativo Circulante/Passivo Circulante

$14-$ Cover = EBITDA (Lucro antes dos Juros, Impostos, Depreciação e Amortização)/Despesas Financeiras

15 - Capacidade de Geração de Caixa (GerCaixa) = EBITDA/Receita Líquida

16 - Liquidez Geral $($ LiqGeral) $=$ (Ativo Circulante + Realizável em Longo Prazo)/(Passivo Circulante + Passivo Não Circulante)

17 - Capital de Giro (CapGiro) $=($ Ativo Circulante Operacional - Passivo Circulante Operacional $) /($ Ativo Circulante - Passivo Circulante)

\section{Operacional}

18 - Crescimento das Vendas $($ CrescRec $)=\left[\left(\right.\right.$ Receita Líquida $_{t} /$ Receita Líquida $\left.\left._{\mathrm{t}-1}\right)-1\right]$

19 - Eficiência Operacional $($ EficOper $)=$ Despesas Operacionais/Receita Líquida 


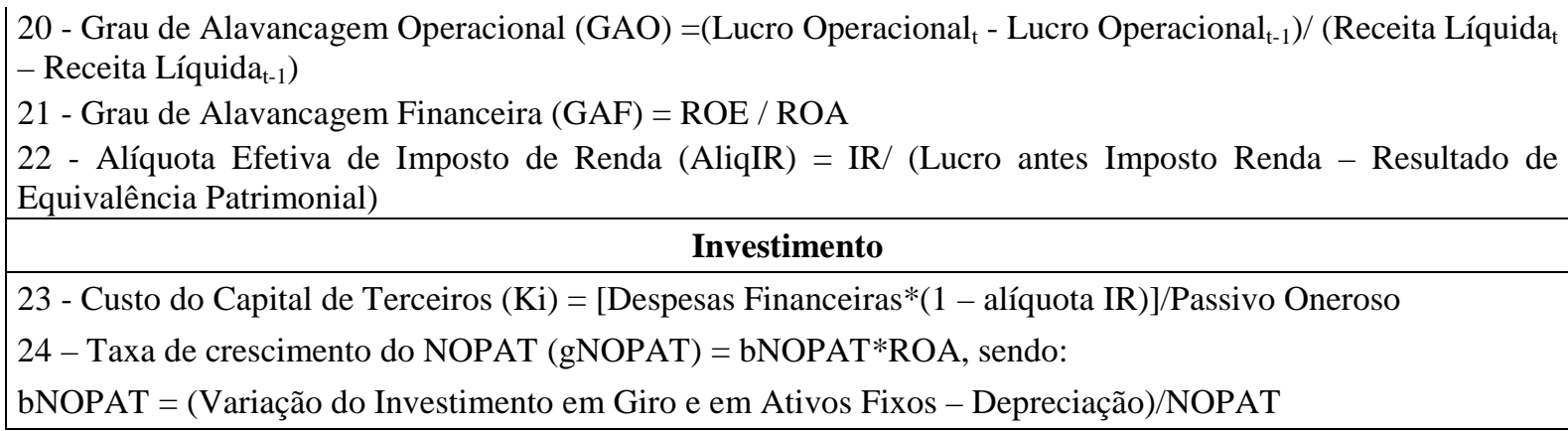
Fonte: Elaborado pelos autores.

\subsection{Coleta de dados}

Os dados foram coletados da base de dados Economática ${ }^{\circledR}$, sendo o critério inicial usado para a coleta a inclusão de todos os demonstrativos anuais de 2000 a 2009 das empresas do setor de energia elétrica, conforme classificação setorial da própria Economática ${ }^{\circledR}$, o que totalizava 54 empresas e 454 demonstrativos financeiros (foram utilizados os balanços consolidados e, quando não disponíveis, os individuais).

O cálculo dos valores do balanço patrimonial de cada empresa em cada ano foi feito da seguinte forma:

$$
\mathrm{X}_{\mathrm{t}}=\left(\mathrm{V}_{\mathrm{t}}+\mathrm{V}_{\mathrm{t}-1}\right) / 2
$$

sendo:

$\mathrm{X}_{\mathrm{t}}=$ valor do item do balanço patrimonial usado para calcular os indicadores financeiros no ano $\mathrm{t}$

$\mathrm{V}_{\mathrm{t}}=$ valor do item do balanço patrimonial no ano $\mathrm{t}$ (por exemplo, valor do ativo circulante da empresa A no ano 2000)

$\mathrm{V}_{\mathrm{t}-1}=$ valor do item do balanço patrimonial no ano $\mathrm{t}-1$ (por exemplo, valor do ativo circulante da empresa A no ano 1999)

Além disso, foram excluídos os demonstrativos anuais que apresentavam pelo menos uma das seguintes características:

- patrimônio líquido negativo no ano em análise ou no ano anterior (t ou t-1);

- algum dado utilizado para cálculo dos indicadores financeiros não divulgado no ano em análise para as contas do balanço patrimonial ou da demonstração de resultado;

- receita líquida zero ou negativa no ano em análise ou no ano anterior (t ou t-1);

- passivo oneroso zero no ano em análise ou no ano anterior (t ou t-1).

Dessa forma, foram coletados dados transversais das empresas em cada um dos dez anos selecionados, de acordo com as características acima citadas, totalizando 52 empresas (exclusão de duas empresas da amostra inicial), o que gerou 385 dados válidos anuais (perda de 15,2\% dos dados iniciais). A Tabela 2 apresenta a distribuição dos dados nos anos. 
A relevância da informação contábil na identificação de empresas criadoras de valor: um estudo do setor...

Tabela 2 - Dados anuais utilizados de 2000 a 2009

\begin{tabular}{rrrr}
\hline & Frequência & Porcentagem & \% Acumulada \\
\hline 2000 & 33 & 8,6 & 8,6 \\
2001 & 32 & 8,3 & 16,9 \\
2002 & 33 & 8,6 & 25,5 \\
2003 & 38 & 9,9 & 35,3 \\
2004 & 39 & 10,1 & 45,5 \\
2005 & 39 & 10,1 & 55,6 \\
2006 & 41 & 10,6 & 66,2 \\
2007 & 43 & 11,2 & 77,4 \\
2008 & 44 & 11,4 & 88,8 \\
2009 & 43 & 11,2 & 100,0 \\
Total & 385 & 100,0 & \\
\hline
\end{tabular}

Fonte: Elaborada pelos autores.

\subsection{Definição das ferramentas de análise}

Para identificar quais são as variáveis que melhor diferenciam as empresas criadoras das destruidoras de valor é necessária a utilização de uma ferramenta estatística que busca estimar a relação entre uma variável não métrica dependente e várias variáveis métricas independentes. Considerando isso, existem duas ferramentas estatísticas que poderiam ser utilizadas: análise discriminante e regressão logística (modelo logit) (HAIR JR. et al., 2005).

A análise discriminante pode ser definida como uma combinação linear de duas (ou mais) variáveis independentes que discriminarão melhor entre os grupos definidos a priori. No entanto, a utilização dessa ferramenta depende estritamente de se atenderem às suposições de normalidade multivariada e de iguais matrizes de variância-covariância nos grupos (HAIR JR. et al., 2005). Portanto, para avaliar a utilização desse método é necessário avaliar inicialmente se os dados levantados atendem aos seus pressupostos.

A Tabela 3 apresenta os testes de normalidade Kolmogorov-Smirnov e Shapiro-Wilk. Pelo teste de Kolmogorov-Smirnov, apenas as variáveis "composição do endividamento" e "giro do ativo" apresentam distribuição normal. Já pelo teste de Shapiro-Wilk, nenhuma das variáveis tem distribuição normal. Isso quer dizer que o primeiro pressuposto da aplicação da análise discriminante não é atendido.

Tabela 3 - Teste de Normalidade das variáveis independentes

\begin{tabular}{ccccccc}
\hline & \multicolumn{3}{c}{ Kolmogorov-Smirnov ${ }^{\mathrm{a}}$} & \multicolumn{3}{c}{ Shapiro-Wilk } \\
& Estatística & G.l. & Sig. & Estatística & G.l. & Sig. \\
\hline IndFinanc & 0,072 & 385 & 0,000 & 0,973 & 385 & 0,000 \\
EndOner & 0,197 & 385 & 0,000 & 0,694 & 385 & 0,000 \\
CompEnd & 0,041 & 385 & 0,147 & 0,960 & 385 & 0,000 \\
EndBanc & 0,116 & 385 & 0,000 & 0,852 & 385 & 0,000 \\
ImobPL & 0,286 & 385 & 0,000 & 0,307 & 385 & 0,000 \\
ImobRNC & 0,051 & 385 & 0,017 & 0,968 & 385 & 0,000 \\
ROA & 0,090 & 385 & 0,000 & 0,925 & 385 & 0,000 \\
ROE & 0,134 & 385 & 0,000 & 0,844 & 385 & 0,000 \\
MargOp & 0,372 & 385 & 0,000 & 0,207 & 385 & 0,000 \\
MargLiq & 0,353 & 385 & 0,000 & 0,295 & 385 & 0,000 \\
GiroAt & 0,037 & 385 & $0,200^{*}$ & 0,982 & 385 & 0,000 \\
GiroPL & 0,324 & 385 & 0,000 & 0,233 & 385 & 0,000 \\
LiqCorr & 0,095 & 385 & 0,000 & 0,939 & 385 & 0,000 \\
Cover & 0,422 & 385 & 0,000 & 0,098 & 385 & 0,000
\end{tabular}


Ana Carolina Costa Corrêa, Alexandre Assaf Neto, Sílvio Hiroshi Nakao e Alyne Anteveli Osajima

\begin{tabular}{ccccccc}
\hline GerCaixa & 0,285 & 385 & 0,000 & 0,350 & 385 & 0,000 \\
LiqGeral & 0,078 & 385 & 0,000 & 0,957 & 385 & 0,000 \\
CapGiro & 0,304 & 385 & 0,000 & 0,339 & 385 & 0,000 \\
CrescRec & 0,275 & 385 & 0,000 & 0,338 & 385 & 0,000 \\
EficOper & 0,378 & 385 & 0,000 & 0,362 & 385 & 0,000 \\
GAO & 0,377 & 385 & 0,000 & 0,277 & 385 & 0,000 \\
GAF & 0,344 & 385 & 0,000 & 0,252 & 385 & 0,000 \\
AliqIR & 0,498 & 385 & 0,000 & 0,030 & 385 & 0,000 \\
Ki & 0,256 & 385 & 0,000 & 0,446 & 385 & 0,000 \\
gNOPAT & 0,090 & 385 & 0,000 & 0,879 & 385 & 0,000 \\
\hline a. Correção da Significância de Lilliefors & & & \\
*. Esta é a parte inferior da real significância. & & & &
\end{tabular}

A Tabela 4 demonstra se existe homogeneidade entre as matrizes de covariância. Considerando-se um nível de significância de 5\%, deve-se rejeitar a hipótese nula, pois, as matrizes são heterogêneas. Assim, o segundo pressuposto da análise também deixou de ser atendido. Observe-se que esse teste é sensível à normalidade das variáveis. Como as variáveis não possuem distribuição normal, o resultado do teste pode estar distorcido.

Tabela 4 - Teste de homogeneidade das matrizes de variância-covariância

\begin{tabular}{llr}
\hline Box's M & & 187,292 \\
& Aprox. & 5,084 \\
F & G.1.1 & 36 \\
& G.1.2 & 400769,611 \\
& Sig. & 0,000 \\
\hline
\end{tabular}

Testa a hipótese nula de matrizes de covariância populacionais iguais. Fonte: Elaborada pelos autores.

Como os pressupostos da análise discriminante não foram atendidos, foi necessária a utilização de uma técnica em que estes não existissem.

Uma ferramenta que apresenta essa característica é a regressão logística. A regressão logística é uma técnica em que a relação entre as variáveis é não linear, já que usa uma relação assumida entre as variáveis independente e dependente que lembra uma curva em forma de "S", conforme mostra a Figura 1 (HAIR JR. et al., 2005).

Figura 1 - Forma da relação logística entre variáveis dependente e independente.
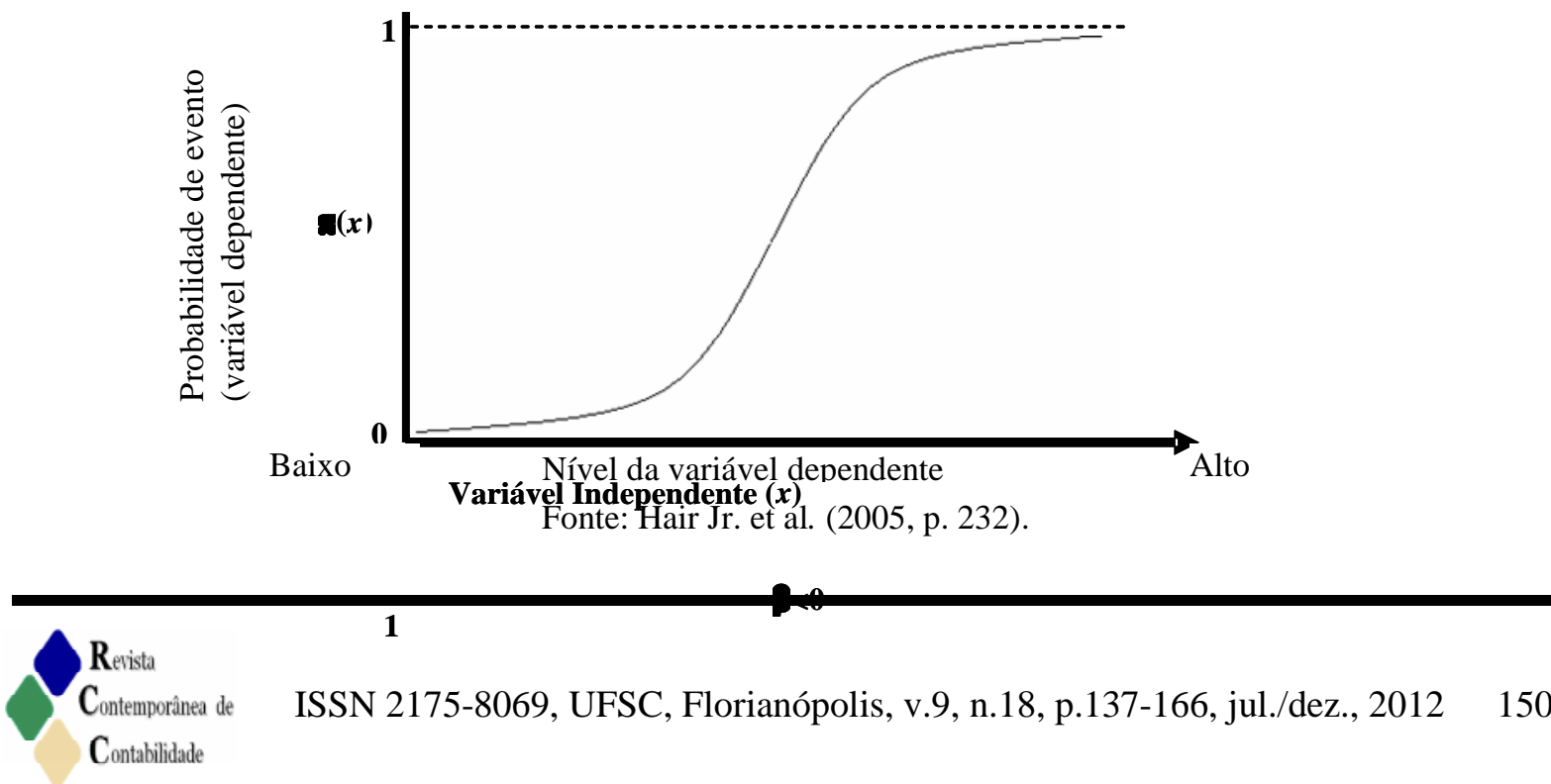
Assim, optou-se pelo uso da regressão logística, pois ela não depende de suposições rígidas, tais como as suposições de normalidade multivariada e de iguais matrizes de variância-covariância nos grupos, e é muito mais robusta quando tais pressupostos não são satisfeitos. Ela também lida com variáveis independentes categóricas facilmente. Além disso, os resultados da regressão logística são similares aos da regressão múltipla nos termos de sua interpretação e medida dos diagnósticos válidos caso a caso para exame dos resíduos (HAIR JR. et al., 2005).

Segundo Penha (2002), há vários tipos de regressão logística: regressão logística binária, multinomial e ordinal. Nesta pesquisa, foi utilizada a regressão logística binária, pois a variável dependente usada no estudo era nominal e binária: empresa criadora (1) ou destruidora de valor (0). As observações com VEA positivo foram classificadas como criadoras de valor, e as observações com VEA negativo, como destruidoras de valor.

A regressão múltipla emprega o método dos mínimos quadrados, o que minimiza a soma das diferenças dos quadrados entre os valores atuais e previstos para a variável dependente. A natureza não linear da transformação logística requer outro procedimento, o da máxima verossimilhança, que é usado de uma maneira interativa para encontrar a melhor estimativa para os coeficientes. Isso resulta no uso do estimador de máxima verossimilhança no lugar da soma dos quadrados quando se calcula as medidas de ajuste do modelo (HAIR JR. et al., 2005). O modelo logístico é baseado na função logística $\mathrm{f}(\mathrm{z})$, dada por (KLEINBAUM, 1996):

sendo,

$$
f(z)=1 /\left(1+e^{-z}\right)
$$

$\mathrm{e}=2,718$

$\mathrm{Z}$ é uma combinação linear das variáveis independentes: $\mathrm{B}_{0}+\mathrm{B}_{1} \mathrm{X}_{1}+\mathrm{B}_{2} \mathrm{X}_{2}+\ldots+\mathrm{B}_{\mathrm{p}} \mathrm{X}_{\mathrm{p}}$;

$\mathrm{B}_{0}$ uma constante e $\mathrm{B}_{1} \ldots \mathrm{B}_{\mathrm{p}}$ coeficientes estimados a partir dos dados;

$\mathrm{X}_{1} \ldots \mathrm{X}_{\mathrm{p}}$ as variáveis independentes.

Os coeficientes estimados são, na verdade, medidas das variações na proporção das probabilidades chamada de razão de desigualdade. Assim, um coeficiente positivo aumenta a probabilidade, enquanto um valor negativo diminui a probabilidade prevista (HAIR JR. et al., 2005).

De acordo com Hair Jr. et al. (2005), o tamanho mínimo recomendado de uma amostra é de cinco observações por variável independente, sabendo que, quanto maior o número de observações, menos instáveis serão os resultados. Neste estudo, foi utilizada uma amostra de 385 observações para um total de 24 variáveis independentes, ou seja, uma média de 16 observações por variável.

O método utilizado para a aplicação da regressão logística foi o Forward Stepwise (Wald), pois, em comparação com o método Enter que analisa e inclui no modelo todas as variáveis independentes, o método Stepwise insere somente as variáveis que são diferenciadoras dos casos, contribuindo efetivamente para a sua classificação e, ao mesmo tempo, identificando quais são as principais características influenciadoras (HAIR JR. et al., 2005). Dessa forma, o software aplica a ferramenta estatística por "passos" (steps), e em cada um deles uma nova variável é incluída até obter a melhor modelagem, fazendo um número de iterações que otimize a porcentagem de acertos. 
Para avaliar o modelo obtido pela ferramenta estatística, optou-se por utilizar o método $k$-fold cross-validation ou validação cruzada. Nessa técnica, divide-se o conjunto de dados disponíveis em $\mathrm{K}$ subconjuntos. O modelo é elaborado com $\mathrm{K}-1$ subconjuntos e validado com o subconjunto restante. $\mathrm{O}$ erro de validação é medido testando-o sobre o subconjunto deixado de fora. Esse procedimento é repetido até que todos os $\mathrm{K}$ subconjuntos sejam avaliados. Assim, é possível calcular uma média da taxa de acerto e seu desvio padrão sobre uma base sempre inédita, obtendo uma estimativa da taxa de acerto verdadeira do modelo (REFAEILZADEH; TANG; LIU, 2009). Devido ao tamanho da base, optou-se por dividi-la em quatro subconjutos.

Além da regressão logística, foi aplicado o teste $t$ para duas amostras independentes para verificar se há diferenças de médias entre as empresas com VEA positivo e as com VEA negativo. O teste t foi escolhido, pois, segundo Pestana e Gageiro (2003), é indicado para verificar se as médias populacionais de dois grupos são estatisticamente iguais quando não se conhece suas variâncias populacionais e pode ser aplicado, quando se trata de amostras maiores de 30 casos, a grupos com distribuições não normais.

Também foi aplicada a correlação de Pearson entre as variáveis independentes e a variável dependente. De acordo com Stevenson (1981), esse teste mede o grau de relacionamento entre duas variáveis contínuas, indicando até que ponto os valores de uma variável estão relacionados com os de outra.

\section{Resultados e Discussão}

\subsection{Análise descritiva do setor de energia elétrica}

A Tabela 5 apresenta uma análise descritiva das empresas em estudo. Observa-se que há elevada variabilidade nas características das companhias do setor, especialmente em relação ao ativo total, ao patrimônio líquido, ao lucro líquido e ao valor econômico agregado, já que seus coeficientes de variação ficaram acima de 2 . Apenas o custo do capital próprio apresentou relativamente menor variabilidade, com uma média de $16,41 \%$ ao ano para o setor.

Tabela 5 - Análise descritiva do setor de energia elétrica

\begin{tabular}{crrcrr}
\hline & $\begin{array}{c}\text { Média } \\
\text { (mil R\$) }\end{array}$ & $\begin{array}{c}\text { Desvio-padrão } \\
\text { (mil R\$) }\end{array}$ & $\begin{array}{c}\text { Coeficiente } \\
\text { de variação }\end{array}$ & $\begin{array}{c}\text { Mínimo } \\
\text { (mil R\$) }\end{array}$ & \multicolumn{1}{c}{$\begin{array}{c}\text { Máximo } \\
\text { (mil R\$) }\end{array}$} \\
\hline Ativo Total & $8.007 .214,6$ & $18.507 .266,2$ & 2,31 & $107.580,0$ & $135.935 .296,0$ \\
Patrimônio Líquido & $3.683 .386,0$ & $11.433 .522,0$ & 3,10 & $20.426,0$ & $83.099 .939,5$ \\
Receita Líquida & $2.739 .207,3$ & $3.722 .552,7$ & 1,36 & 339,0 & $30.066 .350,0$ \\
Lucro Líquido & $265.361,0$ & $617.286,2$ & 2,33 & $-3.417 .524,0$ & $6.149 .330,0$ \\
Ke & $16,41 \%$ & $3,80 \%$ & 0,23 & $10,70 \%$ & $36,36 \%$ \\
VEA & $-281.644,5$ & $1.487 .862,3$ & $-5,28$ & $-12.586 .788,5$ & $1.793 .388,7$ \\
\hline
\end{tabular}

Fonte: Dados da pesquisa.

Conforme descrito na metodologia, item 3.1 deste trabalho, o custo do capital próprio de cada empresa por ano foi calculado de acordo com a fórmula abaixo, a partir dos dados apresentados na Tabela 6:

$\mathrm{Ke}=\mathrm{Rf}+\beta_{\mathrm{u}} *[1+($ Passivo Oneroso/Patrimônio Líquido $) *(1-0,34)] *(\mathrm{Rm}-\mathrm{Rf})+$ Risco-Brasil 
Tabela 6 - Dados utilizados para cálculo do custo do capital próprio (Ke)

\begin{tabular}{ccccc}
\hline Ano & Rf (\%a.a.) $^{\mathbf{a}}$ & Bu $^{\mathbf{b}}$ & Rm (\% a.a.) $^{\mathbf{c}}$ & Risco-Brasil (\% a.a.) $^{\mathbf{d}}$ \\
\hline 2000 & $6,03 \%$ & 0,36 & $12,23 \%$ & $7,23 \%$ \\
2001 & $5,02 \%$ & 0,3183 & $12,23 \%$ & $8,80 \%$ \\
2002 & $4,61 \%$ & 0,36654 & $12,23 \%$ & $12,69 \%$ \\
2003 & $4,02 \%$ & 0,42199 & $12,23 \%$ & $8,03 \%$ \\
2004 & $4,27 \%$ & 0,46482 & $12,23 \%$ & $5,33 \%$ \\
2005 & $4,29 \%$ & 0,5443969 & $12,23 \%$ & $3,95 \%$ \\
2006 & $4,79 \%$ & 0,6349283 & $12,23 \%$ & $2,33 \%$ \\
2007 & $4,63 \%$ & 0,6217418 & $12,23 \%$ & $1,78 \%$ \\
2008 & $3,67 \%$ & 0,4858246 & $12,23 \%$ & $2,83 \%$ \\
2009 & $3,26 \%$ & 0,4778689 & $12,23 \%$ & $2,95 \%$ \\
\hline
\end{tabular}

a. Taxa anual média do T-Note com maturidade de 10 anos dos EUA (IPEADATA, 2011b).

b. Média anual do beta não alavancado das empresas do setor de energia elétrica listadas na NYSE (dados obtidos no software Economática ${ }^{\circledR}$ ).

c. Média de 20 anos do retorno mensal anualizado do índice NYSE (YAHOO FINANCE, 2011).

d. Média anual do risco-Brasil calculado pelo EMBI+ do JP Morgan (IPEADATA, 2011a).

Fonte: Dados da pesquisa.

Segundo a teoria econômica, é possível que o tamanho das empresas interfira na sua geração de valor. Assim, antes da aplicação dos testes, a amostra foi dividida em quatro grupos, com a mesma quantidade de observações cada, de acordo com o valor do ativo total, utilizado como proxy para o tamanho. Os intervalos de confiança resultantes foram:

Tabela 7 - Intervalos de confiança para tamanho

\begin{tabular}{ccc}
\hline Intervalo de Confiança & $\mathbf{n}^{\circ}$ observações & Valor do Ativo Total da Empresa \\
\hline Tamanho 1 & 96 & Até R $\$ 2,146$ bilhões \\
Tamanho 2 & 96 & De R $\$ 2,146$ a R $\$ 3,33$ bilhões \\
Tamanho 3 & 96 & De R $\$ 3,33$ a R $\$ 6,46$ bilhões \\
Tamanho 4 & 97 & Acima de R $\$ 6,46$ bilhões \\
\hline
\end{tabular}

Fonte: Dados da pesquisa.

A Tabela 8 mostra a porcentagem de empresas que apresentaram VEA positivo e VEA negativo em cada grupo de tamanho. Do total de 385 dados em análise, apenas 161 deles apresentaram VEA positivo, ou seja, houve geração de valor em $41,82 \%$ dos casos.

Tabela 8 - Porcentagem de empresas com VEA positivo e negativo por tamanho

\begin{tabular}{ccccccc}
\hline & \multicolumn{2}{c}{ VEA negativo } & \multicolumn{2}{c}{ VEA positivo } & \multicolumn{2}{c}{ Total } \\
\cline { 2 - 7 } & $\begin{array}{c}\mathbf{N}^{\circ} \\
\text { observações }\end{array}$ & \% Total & $\begin{array}{c}\mathbf{N}^{\circ} \\
\text { observações }\end{array}$ & \% Total & $\begin{array}{c}\mathbf{N}^{\circ} \\
\text { observações }\end{array}$ & \% Total \\
\hline Tamanho 1 & 62 & $64,6 \%$ & 34 & $35,4 \%$ & 96 & $25 \%$ \\
Tamanho 2 & 55 & $57,3 \%$ & 41 & $42,7 \%$ & 96 & $25 \%$ \\
Tamanho 3 & 47 & $49,0 \%$ & 49 & $51,0 \%$ & 96 & $25 \%$ \\
Tamanho 4 & 60 & $61,9 \%$ & 37 & $38,1 \%$ & 97 & $25 \%$ \\
\hline Total & $\mathbf{2 2 4}$ & $\mathbf{5 8 , 2 \%}$ & $\mathbf{1 6 1}$ & $\mathbf{4 1 , 8 \%}$ & $\mathbf{3 8 5}$ & $\mathbf{1 0 0 \%}$ \\
\hline
\end{tabular}

Fonte: Dados da pesquisa.

Para verificar se a geração de valor apresentada na Tabela 8 era significativamente diferente entre os quatro grupos, foram aplicados dois testes: a análise de variância e o teste não paramétrico de Kruskal Wallis (estatística Qui-quadrado), cujos resultados são mostrados respectivamente nas Tabelas 9 e 10. Ambos indicaram que se deve aceitar a hipótese nula de 
que a geração de valor é estatisticamente igual nos quatro grupos, ou seja, o tamanho não é uma variável considerada relevante nesse contexto.

Tabela 9 - ANOVA - Diferença de médias do VEA em relação ao tamanho

\begin{tabular}{|c|c|c|c|c|c|}
\hline & $\begin{array}{c}\text { Soma de } \\
\text { quadrados }\end{array}$ & G.l. & $\begin{array}{l}\text { Quadrado da } \\
\text { média }\end{array}$ & $\mathbf{F}$ & Sig. \\
\hline Entre grupos & 1,349 & 3 & 0,450 & 1,855 & 0,137 \\
\hline Dentro grupos & 92,324 & 381 & 0,242 & & \\
\hline Total & 93,673 & 384 & & & \\
\hline
\end{tabular}

Fonte: Dados da pesquisa.

Tabela 10 - Teste Kruskal-Wallis (Qui-quadrado) para diferença de médias do VEA em relação ao tamanho

\begin{tabular}{lr}
\hline \multicolumn{2}{c}{ Estatísticas do Teste $^{\mathbf{a}, \mathbf{b}}$} \\
\hline \multicolumn{2}{c}{ VEA } \\
\hline Qui-quadrado & 5,529 \\
G.l. & 3 \\
Asymp. Sig. & 0,137 \\
\hline a. Teste Kruskal Wallis & b. Variável de agrupamento: Tamanho \\
Fonte: Dados da pesquisa. &
\end{tabular}

Ao comparar as médias das principais contas das empresas que apresentaram VEA negativo com as que apresentaram VEA positivo por meio da aplicação do teste $t$ para diferença de médias (Tabela 11), observa-se que as empresas destruidoras de valor são maiores em termos de ativo total e patrimônio líquido. A receita líquida é similar nos dois grupos, ou seja, as médias não são diferentes em um nível de significância de $5 \%$ (p-valor de $21 \%$ ). Porém, o lucro líquido e o VEA são maiores nas empresas geradoras de valor, enquanto que seu custo de capital próprio é menor. Isso significa que elas apresentam maior rentabilidade absoluta (lucro líquido) e especialmente em relação ao capital investido.

\section{Tabela 11 - Teste t - Análise descritiva comparando empresas geradoras das destruidoras de valor (em milhares de reais e o Ke em \% ao ano)

\begin{tabular}{lrr}
\hline & VEA Negativo & VEA Positivo \\
\hline Ativo Total $^{*}$ & 9.769 .260 & 5.555 .673 \\
Patrimônio Líquido $^{*}$ & 4.937 .770 & 1.938 .156 \\
Receita Líquida & 2.552 .884 & 2.998 .440 \\
Lucro Líquido $^{*}$ & 72.153 & 534.172 \\
VEA $^{*}$ & -672.512 & 262.171 \\
Ke $^{*}$ & $17,08 \%$ & $15,47 \%$ \\
\hline
\end{tabular} \\ * $1 \%$ nível de significância - Teste t para amostras independentes (bicaudal) \\ Fonte: Dados da pesquisa.}

A Tabela 12 apresenta a correlação entre os indicadores financeiros e o VEA. Observa-se que as variáveis que foram consideradas significativamente correlacionadas a um nível de significância de 5\% foram: independência financeira, índice de endividamento oneroso, composição do endividamento, composição do endividamento bancário, retorno 
sobre o ativo, retorno sobre patrimônio líquido, giro do ativo, eficiência operacional e grau de alavancagem operacional.

Tabela 12 - Correlação entre os indicadores financeiros e o VEA

\begin{tabular}{lccccc}
\hline & VEA & & & VEA \\
\cline { 1 - 2 } \cline { 5 - 5 } IndFinanc & $-0,258^{*}$ & & LiqCorr & $-0,045$ \\
EndOner & $0,102^{* *}$ & & Cover & 0,022 \\
CompEnd & $0,250^{*}$ & & GerCaixa & 0,043 \\
EndBanc & $0,130^{* *}$ & & LiqGeral & 0,041 \\
ImobPL & 0,044 & & CapGiro & $-0,012$ \\
ImobRNC & $-0,095$ & & CrescRec & 0,010 \\
ROA & $0,308^{*}$ & & EficOper & $-0,185^{*}$ \\
ROE & $0,242^{*}$ & & GAO & $-0,142^{*}$ \\
MargOp & 0,037 & & GAF & 0,051 \\
MargLiq & 0,059 & & AliqIR & $-0,004$ \\
GiroAt & $0,313^{*}$ & & Ki cont & 0,029 \\
GiroPL & 0,084 & & gNOPAT & 0,054 \\
\hline
\end{tabular}

* Correlação é significante a $\overline{1 \% \text { nível de significância (bicaudal) }}$

** Correlação é significante a 5\% nível de significância (bicaudal)

Fonte: Dados da pesquisa.

Na Tabela 13, pode-se verificar as médias de cada variável independente para o grupo de empresas geradoras de valor (VEA positivo) e para o grupo de empresas destruidoras de valor (VEA negativo). Por meio da aplicação do teste $t$ para diferença de médias, observa-se que os indicadores que apresentam médias significativamente diferentes a $1 \%$ de nível de significância para os grupos são: independência financeira, composição do endividamento, composição do endividamento bancário, imobilização de recursos não correntes, retorno sobre o ativo, retorno sobre o patrimônio líquido, margem líquida, giro do ativo, giro do patrimônio líquido, liquidez corrente, cover, liquidez geral, grau de alavancagem financeira e taxa de crescimento do NOPAT.

Tabela 13 - Teste $\mathrm{t}$ - Diferença das médias dos indicadores financeiros das empresas criadoras e das destruidoras de valor

\begin{tabular}{lcc}
\hline & VEA Negativo & VEA Positivo \\
\hline IndFinanc $^{*}$ & 0,40 & 0,32 \\
EndOner $^{* *}$ & 1,08 & 1,37 \\
CompEnd* $^{*}$ & 0,36 & 0,41 \\
EndBanc $^{*}$ & 0,30 & 0,22 \\
ImobPL & 2,00 & 2,19 \\
ImobRNC & 0,80 & 0,72 \\
ROA* & 0,06 & 0,14 \\
ROE & $-0,04$ & 0,39 \\
MargOp & 0,21 & 0,30 \\
MargLiq & $-0,13$ & 0,24 \\
GiroAt & 0,37 & 0,58 \\
GiroPL & 1,35 & 2,80 \\
LiqCorr $^{*}$ & 0,92 & 1,08 \\
Cover & 0,17 & 3,40 \\
GerCaixa & 0,29 & 0,38 \\
LiqGeral & 0,64 & 0,73
\end{tabular}




$\begin{array}{lcc}\text { CapGiro } & -0,48 & 0,23 \\ \text { CrescRec } & 0,15 & 0,13 \\ \text { EficOper } & 0,24 & 0,09 \\ \text { GAO } & -0,04 & 0,00 \\ \text { GAF } & -2,22 & 2,86 \\ \text { AliqIR } & -5,37 & 0,26 \\ \text { Ki }^{* * *} & 0,23 & 0,17 \\ \text { gNOPAT }^{*} & 0,02 & 0,05 \\ \text { * 1\% nível de significância - Teste t para amostras independentes (bicaudal) } \\ \text { ** 5\% nível de significância - Teste t para amostras independentes (bicaudal) } \\ \text { Fonte: Dados da pesquisa. }\end{array}$

\subsection{Regressão Logística}

Mediante a aplicação do teste Qui-Quadrado, a Tabela 14 demonstra se os coeficientes do modelo são significativos. Considerando um nível de significância de 5\%, pode-se afirmar que estes são estatisticamente significativos.

Tabela 14 - Significância dos coeficientes do modelo Teste Omnibus dos Coeficients do Modelo

\begin{tabular}{llrrr}
\hline & & $\begin{array}{c}\text { Qui- } \\
\text { quadrado }\end{array}$ & G.1. & Sig. \\
\hline \multirow{3}{*}{ Passo 6 } & Passo & 5,393 & 1 & 0,000 \\
& Bloco & 505,102 & 5 & 0,000 \\
& Modelo & 505,102 & 5 & 0,000 \\
\hline
\end{tabular}

Fonte: Dados da pesquisa.

A Tabela 15 se relaciona à adequação do modelo. O -2LL (Log likelihood) ideal é igual a zero. Nesse caso, apesar de não ser zero, o modelo apresenta uma boa adequação, já que seu -2LL é 18,266, valor considerado baixo. O R ${ }^{2}$ de Cox e Snell e de Nagelkerke são comparáveis com a medida do $\mathrm{R}^{2}$ em regressão múltipla (proporção de variância da variável dependente que é explicada pelas variáveis independentes). Segundo Hair Jr. et al. (2005), a medida de Cox e Snell é limitada, pois, apesar de ser do tipo quanto maior, melhor, ela não pode alcançar o valor máximo de 1 . Já o $\mathrm{R}^{2}$ de Nagelkerke varia entre zero e um, fornecendo melhor interpretação do resultado. Nesse caso, o $\mathrm{R}^{2}$ de Nagelkerke foi de $98,3 \%$, indicando um excelente ajuste.

Tabela 15 - Adequação do modelo

\begin{tabular}{|c|c|c|c|c|}
\hline Passo & & $\begin{array}{l}-2 \text { Log } \\
\text { likelihood }\end{array}$ & $\begin{array}{c}\text { Cox \& } \\
\text { Snell } R^{2}\end{array}$ & $\begin{array}{c}\text { Nagelkerke } \\
\mathrm{R}^{2}\end{array}$ \\
\hline & 6 & $18,266^{\mathrm{a}}$ & 0,731 & 0,983 \\
\hline
\end{tabular}

a. A estimação terminou na iteração número 15 porque a estimativa do parâmetro mudou menos de 0,001 . Fonte: Dados da pesquisa.

A Tabela 16 mostra o ajuste final do modelo pela estatística Hosmer e Lemeshow, o qual mede a correspondência entre os valores reais e os previstos da variável dependente. Aqui, um melhor ajuste do modelo é apontado por uma menor diferença entre a classificação observada e a prevista. Assim, um bom ajuste do mesmo é indicado por um valor quiquadrado não significante. Como o valor de P ("Sig." na tabela) é 1,000, pode-se dizer que o ajuste do modelo é bom, pois não é significativo em um nível de significância de 5\%. 
Tabela 16 - Medida de ajuste do modelo - Estatística Hosmer e Lemeshow

\begin{tabular}{cccc}
\hline Passo & Qui-quadrado & G.1. & Sig. \\
\hline 6 & 0,039 & 7 & 1,000 \\
\hline \multicolumn{3}{l}{ Fonte: Dados da pesquisa. }
\end{tabular}

A Tabela 17 apresenta a porcentagem de acerto do modelo ao ser aplicado na própria amostra usada para fazer a modelagem, que foi de $98,7 \%$ dos casos.

Tabela 17 - Validação do modelo - Tabela de classificação

\begin{tabular}{|c|c|c|c|c|c|}
\hline & \multirow{3}{*}{\multicolumn{2}{|c|}{ Observado }} & \multicolumn{3}{|c|}{ Previsto } \\
\hline & & & \multicolumn{2}{|c|}{ VEA } & \multirow{2}{*}{$\begin{array}{c}\text { Porcentagem } \\
\text { Correta }\end{array}$} \\
\hline & & & Negativo & Positivo & \\
\hline \multirow{3}{*}{ Passo 6} & \multirow{3}{*}{ VEA } & Negativo & 221 & 3 & 98,70 \\
\hline & & Positivo & 2 & 159 & 98,80 \\
\hline & & \multicolumn{2}{|c|}{ Porcentagem Geral } & & 98,70 \\
\hline
\end{tabular}

a. $\mathrm{O}$ valor de corte é 0,500

Fonte: Dados da pesquisa.

A Tabela 18 mostra os valores estimados dos coeficientes que serão utilizados para especificar o modelo, seus desvios-padrão e os valores P (Sig.). Pela Tabela, observa-se que as variáveis que foram incluídas no modelo, e que, portanto, são mais relevantes para discriminar as empresas geradoras de valor nesse setor, foram a independência financeira, a composição do endividamento, a composição do endividamento bancário, o retorno sobre o patrimônio líquido e o crescimento da receita líquida.

Os valores de $\mathrm{P}$ testam a hipótese nula de que os parâmetros são iguais a zero versus estes parâmetros sendo diferentes de zero. Assim, observamos que as variáveis independência financeira, composição do endividamento bancário e retorno sobre o patrimônio líquido são as que são significativas em um nível de significância de 5\%, porém, se adotar um nível de significância de $10 \%$, as outras variáveis incluídas no modelo também podem ser consideradas estatisticamente significativas.

De acordo com o teste estatístico Wald, o coeficiente mais significativo (mais importante para influenciar a geração de valor) é o retorno sobre o patrimônio líquido, em segundo lugar, a composição do endividamento bancário seguido de independência financeira, composição do endividamento e, por último, o crescimento da receita.

Tabela 18 - Variáveis independentes na equação

\begin{tabular}{lrrrrrrrr}
\hline & \multirow{2}{*}{$\mathrm{B}$} & S.E. & \multirow{2}{*}{ Wald } & G.l. & Sig. & \multirow{2}{*}{$\operatorname{Exp}(\mathrm{B})$} & \multicolumn{2}{c}{ 95\% I.C.para EXP(B) } \\
\cline { 7 - 10 } & & & & & & Abaixo & \multicolumn{1}{c}{ Acima } \\
\hline IndFinanc & 31,141 & 13,384 & 5,413 & 1 & 0,02 & $3,34 \mathrm{E}+13$ & 135,358 & $8,26 \mathrm{E}+24$ \\
CompEnd & 19,418 & 11,305 & 2,95 & 1 & 0,09 & $2,71 \mathrm{E}+08$ & 0,065 & $1,14 \mathrm{E}+18$ \\
EndBanc & $-26,406$ & 11,158 & 5,601 & 1 & 0,02 & 0 & 0 & 0,011 \\
ROE & 289,81 & 111,11 & 6,804 & 1 & 0,01 & $7,28 \mathrm{E}+125$ & $1,94 \mathrm{E}+31$ & $2,74 \mathrm{E}+220$ \\
CrescRec & $-8,171$ & 4,887 & 2,796 & 1 & 0,10 & 0 & 0 & 4,082 \\
Constante & $-53,608$ & 20,424 & 6,889 & 1 & 0,01 & 0 & & \\
\hline
\end{tabular}

Fonte: Dados da pesquisa.

A equação da regressão logística para este estudo foi:

$\mathrm{Z}=-53,608+31,141 *$ IndFinanc $+19,418 *$ CompEnd $-26,406 *$ EndBanc $+289,808 * \mathrm{ROE}-$ $8,171 *$ CrescRec 
Isso quer dizer que a equação final, ou seja, a que calcula a probabilidade da empresa ser criadora de valor em um determinado ano, ou seja, obter VEA positivo, é a seguinte:

$$
\begin{gathered}
\text { P(VEA positivo })=1 /\left(1+\mathrm{e}^{-\mathrm{Z}}\right)= \\
=1 /\left(1+\mathrm{e}^{-(-53,608+31,141 * \text { IndFinanc }+19,418 * \text { CompEnd }-26,406 * \text { EndBanc }+289,808 * \mathrm{ROE}-8,171 * \text { CrescRec })}\right)
\end{gathered}
$$

\subsection{Validação do modelo}

Para melhor validação do teste, foi aplicado o método $k$-fold cross validation. Assim, a amostra foi dividida em quatro partes iguais, treinando-se o modelo com $75 \%$ da amostra e avaliando-se com a parte restante. A divisão da amostra foi feita aleatoriamente pelo software estatístico, tendo preservado a proporção dos grupos da variável dependente (VEA negativo e positivo) em cada parte. Com isso, foi possível verificar a precisão do modelo, ou seja, a porcentagem de acerto em uma amostra "nova" (com dados não utilizados para a modelagem). Conforme mostra a Tabela 19, o modelo previu corretamente em média 97,15\% dos casos reais, com um desvio padrão de $1,55 \%$, o que resulta em um erro médio de $2,85 \%$.

Tabela 19-4-fold cross validation

\begin{tabular}{ccccccc}
\hline Rodadas & 1 & 2 & 3 & 4 & Média & Desvio Padrão \\
\hline Acerto & $96,90 \%$ & $97,90 \%$ & $99,00 \%$ & $94,80 \%$ & $\mathbf{9 7 , 1 5 \%}$ & $\mathbf{1 , 5 5 \%}$ \\
\hline
\end{tabular}

Fonte: Dados da pesquisa.

\subsection{Análise dos resultados}

A Tabela 20 compara os resultados dos três testes aplicados (correlação, teste t para diferença de médias e a regressão logística). Pode-se observar que três tipos de indicadores são mais relevantes para a geração de valor: a rentabilidade, representada pelo retorno sobre o patrimônio líquido, pelo retorno sobre o ativo e pelo giro do ativo; o endividamento, representado pela composição do endividamento bancário, independência financeira, composição do endividamento e índice de endividamento oneroso; e o operacional, representado pela eficiência operacional.

Tabela 20 - Comparação dos resultados dos três testes - Nível de significância de 5\%

\begin{tabular}{cccccc}
\hline Nome & Código & Sinal & Correlação & Teste t & Regressão Logística \\
\hline Independência Financeira & IndFinanc & - & $\mathrm{X}$ & $\mathrm{X}$ & $\mathrm{X}$ \\
Composição do Endividamento & CompEnd & + & $\mathrm{X}$ & $\mathrm{X}$ & $\mathrm{X}^{*}$ \\
Composição do Endividamento Bancário & EndBanc & - & $\mathrm{X}$ & $\mathrm{X}$ & $\mathrm{X}$ \\
Retorno sobre o Patrimônio Líquido & $\mathrm{ROE}$ & + & $\mathrm{X}$ & $\mathrm{X}$ & $\mathrm{X}$ \\
Índice de Endividamento Oneroso & EndOner & + & $\mathrm{X}$ & $\mathrm{X}$ & \\
Retorno sobre o Ativo & ROA & + & $\mathrm{X}$ & $\mathrm{X}$ & \\
Giro do Ativo & GiroAt & + & $\mathrm{X}$ & $\mathrm{X}$ & \\
Eficiência Operacional & EficOper & - & $\mathrm{X}$ & $\mathrm{X}$ & \\
\hline
\end{tabular}

*Significante a 10\% de nível de significância.

Fonte: Dados da pesquisa.

Porém, dos oito indicadores destacados apenas quatro foram considerados estatisticamente significativos para discriminar os grupos pelos três testes, sendo: independência financeira, composição do endividamento, composição do endividamento 
bancário e retorno sobre o patrimônio líquido. As outras quatro variáveis, apesar de não terem sido selecionadas na regressão, foram consideradas significativas pelos outros dois testes.

A inclusão do retorno sobre o patrimônio líquido como sendo a variável mais relevante para a identificação das empresas que geram valor tem sentido econômico, pois, teoricamente, a rentabilidade apresenta relação positiva com a geração de valor e, dentre as medidas de rentabilidade, o retorno sobre o patrimônio líquido é o indicador mais importante para os investidores, já que reflete seu ganho.

A composição do endividamento bancário, segunda variável identificada em ordem de importância pela regressão logística, está negativamente relacionada à geração de valor, isto quer dizer que quanto mais longo o prazo para pagamento das dívidas (passivo oneroso), maior o valor criado ao acionista. Além disso, no Brasil o custo da dívida está mais relacionado às fontes de financiamento do que às características do empréstimo. Assim, contrariando a teoria da estrutura temporal das taxas de juros, muitas vezes os empréstimos e financiamentos de longo prazo apresentam menores custos do que os de curto prazo. Isso ocorre, pois a maioria dos empréstimos de longo prazo no Brasil são subsidiados, como os do BNDES (Banco Nacional de Desenvolvimento Econômico e Social). Especialmente no setor de energia elétrica, em que, por ser considerado de utilidade pública, há financiamentos de longo prazo subsidiados pelo governo.

$\mathrm{O}$ indicador de independência financeira apresenta relação negativa com a geração de valor. Do ponto de vista estritamente financeiro, quanto menor essa relação, menor a liberdade de decisões financeiras da empresa ou maior a dependência a recursos de terceiros. Por outro lado, do ponto de vista de obtenção de lucro ou até mesmo da geração de valor, a alavancagem financeira pode ser vantajosa (MATARAZZO, 2003). Conforme descrito no referencial teórico, as empresas buscam uma estrutura ótima de capital, já que a alavancagem traz tanto benefícios quanto custos. No caso do setor de energia elétrica em análise, empiricamente verificou-se que a alavancagem financeira foi positivamente relacionada à geração de valor, indicando que a remuneração paga a esses capitais de terceiros foi menor do que o lucro conseguido com a sua aplicação nos negócios.

A relação positiva entre a composição do endividamento e a geração de valor, indicando que, quanto mais de curto prazo for o passivo, maior o VEA, aparentemente pode parecer contrária ao esperado. Porém, ao analisar o indicador, verifica-se que o passivo circulante é composto por passivo oneroso e não oneroso. E a verdadeira relação por trás é quanto maior a participação do passivo não oneroso, maior a geração de valor, conforme mostra a Tabela 21, já que a média da participação do passivo operacional no passivo circulante é significativamente superior nas empresas geradoras de valor.

Tabela 21 - Teste $\mathbf{t}$ - Médias do passivo circulante financeiro e operacional das empresas geradoras e destruidoras de valor

\begin{tabular}{lllrrr}
\hline & VEA & N & Média & Desvio-padrão & Erro-padrão médio \\
\hline \multirow{2}{*}{ PCO/PC** $*$ Negativo } & 224 & 0,632 & 0,20895 & 0,01396 \\
& Positivo & 161 & 0,748 & 0,15534 & 0,01224 \\
\hline \multirow{2}{*}{ PCF/PC* } & Negativo & 224 & 0,368 & 0,20895 & 0,01396 \\
& Positivo & 161 & 0,252 & 0,15534 & 0,01224 \\
\hline
\end{tabular}

* $1 \%$ nível de significância - Teste t para amostras independentes Fonte: Dados da pesquisa. 
Em dezembro de 1996, foi criada a ANEEL (Agência Nacional de Energia Elétrica), responsável pela regulação do setor, especialmente em relação às tarifas. O Brasil adota o regime de tarifação price cap ou preço-teto. A firma regulada nessa abordagem estará limitada a perseguir a eficiência operacional, diminuindo seus custos ou aumentando a eficiência de utilização de seus ativos, em busca da geração de valor. Isso acontece porque os preços não são determinados pelos custos adicionais incorridos (SILVA, 2007).

Diante desse cenário, era de se esperar que o indicador margem operacional fosse relevante para discriminar as empresas geradoras de valor. Porém os resultados dos testes mostram-no estatisticamente não significativo. Uma das explicações possíveis é a dificuldade em reduzir custos em um setor regulado.

Caso os preços estivessem abaixo do nível mínimo necessário para cobrir os custos, haveria um forte incentivo para subinvestimento e/ou racionamento da oferta (para o segmento de geração de energia). No caso das prestadoras de serviço (distribuidoras de energia), isso se manifestaria com uma queda na qualidade do serviço. Porém, como é uma indústria regulada, seu pacote específico de produto/serviço ofertado já estará delineado pelos níveis mínimos de padrão exigidos pelo regulador para a qualidade do fornecimento (SERRATO, 2006).

Já o crescimento das vendas, esperava-se inicialmente que tivesse uma relação positiva e significativa com o VEA, pois quanto maior a receita, maior seria a geração de valor. Porém o teste de diferença de médias não indicou diferença estatisticamente significativa, a sua correlação com o VEA também não se apresentou significativa e a regressão logística o indicou como significativo apenas ao nível de $10 \%$ de significância e com sinal negativo.

Esse resultado pode ser explicado pelo fato de ser um setor regulado pela impossibilidade das empresas em ajustar o preço aos seus custos. Isso também ocorre em licitações e contratos de prestações de serviços. Muitas vezes, a empresa não pode reduzir a oferta, mesmo que a receita extra não seja suficiente para cobrir os dispêndios. Ademais, outro ponto a destacar é quanto ao aumento de receita. Para sua ocorrência, podem ser necessários altos investimentos em ativos fixos, cujos gastos podem ultrapassar os benefícios obtidos com a mudança.

Dessa forma, ao se relacionarem os resultados obtidos à teoria de Value-Relevance, pode-se dizer que as informações contábeis mais relevantes para discriminar as empresas de capital aberto geradoras de valor do setor de energia elétrica brasileiro são: o lucro líquido, o patrimônio líquido, o ativo total, o passivo circulante, o passivo financeiro de curto e longo prazo, a receita líquida e as despesas operacionais.

\section{Considerações Finais}

De acordo com a teoria de Finanças, o objetivo principal da empresa é a criação de riqueza aos acionistas. Por sua vez, a Contabilidade tem como um dos seus princípios a relevância da informação contábil para a tomada de decisões.

Assim, em busca da verificação da relevância das informações contábeis para a identificação da criação de valor, este estudo testou quais indicadores contábeis são mais relevantes na discriminação das empresas geradoras de valor, utilizando como pilares a teoria do Value-Relevance e a medida Valor Econômico Agregado (VEA). 
Para isso, o setor de energia elétrica foi usado como estudo de caso pela sua importância econômica para o País. Essa análise empírica contou com uma amostra de 52 empresas de capital aberto com ações negociadas na BM\&FBOVESPA, no período de 2000 a 2009, totalizando 385 demonstrativos anuais. Com esse propósito, foram utilizados 24 indicadores financeiros de forma a refletir as principais estratégias da empresa ligadas a estrutura de capital, rentabilidade, liquidez, operação e investimento.

Do total de dados em análise, apenas 161 deles apresentaram VEA positivo, ou seja, houve geração de valor em 41,82\% dos casos. Ao comparar as médias das empresas que apresentaram VEA negativo com as que apresentaram VEA positivo, observa-se que as empresas destruidoras de valor são maiores em termos de ativo total e patrimônio líquido. A receita líquida é similar nos dois grupos. Porém o lucro líquido e o VEA são maiores nas empresas geradoras de valor, enquanto que seu custo de capital próprio é menor. Isso significa que elas apresentam maior rentabilidade absoluta (lucro líquido) e em relação ao capital investido.

Além disso, os resultados indicam que três tipos de indicadores são mais relevantes para a geração de valor: a rentabilidade, representada pelo retorno sobre o patrimônio líquido, pelo retorno sobre o ativo e pelo giro do ativo; o endividamento, representado pela composição do endividamento bancário, independência financeira, composição do endividamento e índice de endividamento oneroso; e o operacional, representado pela eficiência operacional.

Porém dos oito indicadores destacados apenas quatro foram considerados estatisticamente significativos ao nível de 5\% de significância para discriminar os grupos pelos três testes realizados (correlação, teste t para diferença de médias e regressão logística), sendo eles: independência financeira, composição do endividamento, composição do endividamento bancário e retorno sobre o patrimônio líquido. As outras quatro variáveis, apesar de não terem sido selecionadas na regressão, foram consideradas significativas pelos outros dois testes.

Assim, ao relacionar os resultados obtidos à teoria de Value-Relevance, pode-se dizer que as informações contábeis mais relevantes para discriminar as empresas de capital aberto geradoras de valor do setor de energia elétrica brasileiro são: o lucro líquido, o patrimônio líquido, o ativo total, o passivo circulante, o passivo financeiro de curto e longo prazo, a receita líquida e as despesas operacionais.

Uma das limitações deste trabalho foi a não inclusão de todas as possíveis variáveis que apresentam influência na criação de valor. Assim, não se pode afirmar que as variáveis identificadas no estudo são as únicas que influenciam ou que são relevantes para a discriminação das empresas geradoras de valor. Como futuros estudos, sugere-se a comparação com outros setores para avaliar se há diferença entre eles.

\section{Referências}

ALALI, F. A.; FOOTE, P. S. The Value Relevance of International Financial Reporting Standards: Empirical Evidence in an Emerging Market. The International Journal of Accounting, v. 47, p. 85-108, 2012.

AL-HARES, O. M.; ABUGHAZALEH, N. M.; HADDAD, A. E. Value relevance of earnings, book value and dividends in an emerging capital market: Kuwait evidence. Global 
Finance Journal, 2012. Disponível em: 〈http://dx.doi.org/10.1016/j.gfj.2012.10.006>. Acesso em: 19 nov. 2012.

ALI, A.; HWANG, L. S. Country-specific factors related to financial reporting and the value relevance of accounting data. Journal of Accounting Research, v. 38, n. 1, p. 1-21, 2000.

ARAÚJO, A. M. P. O estudo de variáveis econômicas e o impacto no comportamento de medida contábil de desempenho (LL) e medida de valor (EVA) - Um estudo empírico. 2005. 156 f. Tese de Livre-Docência, Faculdade de Economia, Administração e Contabilidade de Ribeirão Preto da Universidade de São Paulo, Ribeirão Preto, 2005.

ASSAF NETO, A. Contribuição ao estudo da avaliação de empresas no Brasil - Uma aplicação prática. 2003. 202 f. Tese de Livre-Docência, Faculdade de Economia, Administração e Contabilidade de Ribeirão Preto da Universidade de São Paulo, Ribeirão Preto, 2003.

ASSAF NETO, A. Finanças Corporativas e Valor. 5. ed. São Paulo: Atlas, 2010.

BALL, R.; BROWN, P. An empirical evaluation of accounting income numbers. Journal of Accounting Research, v. 6, p. 159-177, 1968.

BLACCONIERE, W. G.; JOHNSON, M. F.; JOHNSON, M. S. Market valuation and deregulation of electric utilities. Journal of Accouting and Economics, v. 29, p. 231-260, 2000 .

BLOXHAM, E. Economic Value Management: Applications and Techniques. New Jersey: John Wiley \& Sons, 2003.

BM\&FBOVESPA. Informe técnico - Dezembro/2001 a Dezembro/2009 - Valor de Mercado - Valor de Mercado por Setor de Atividade. BM\&FBOVESPA (Bolsa de Valores de São Paulo), 2012. Disponível em: 〈www.bmfbovespa.com.br〉. Acesso em: 16 nov. 2012.

BONIZIO, R. C. Análise de sensibilidade do valor econômico agregado: um estudo aplicado nas empresas de capital aberto no Brasil. 2005. 117 f. Tese de Doutorado, Faculdade de Economia, Administração e Contabilidade da Universidade de São Paulo, São Paulo, 2005.

CABELLO, O. G.; PARISI, C. Análise das Práticas de Gestão Baseada em Valor: Um Estudo de Caso em Usina Açucareira do Brasil. Revista Contemporânea de Contabilidade, UFSC, Florianópolis, ano 5, v. 1, n.9, p. 113-130, jan./jun. 2008.

CHALMERS, K.; NAVISSI, F.; QU, W. Value relevance of accounting information in China pre - and post - 2001 accounting reforms. Managerial Auditing Journal, v. 25, n.8, p. 792$813,2010$.

CHEN, C. J. P.; CHEN, S.; SU, X. Is accounting information value relevant in the emerging Chinese stock market? Journal of International Accounting, Auditing and Taxation, v. 10, n. 1, p. 1-22, 2001.

COLLINS, D. W.; KOTHARI, S. P. An analysis of intertemporal and cross-sectional determinants of earnings response coefficients. Journal of Accounting and Economics, v. 11, n. 2-3, p. 143-181, 1989. 
COLLINS, D. W.; MAYDEW, E. L.; WEISS, I. S. Changes in the value-relevance of earnings and the book values over the past forty years. Journal of Accounting and Economics, v. 24, n. 1, p. 39-67, 1997.

COMITÊ DE PRONUNCIAMENTOS CONTÁBEIS (CPC). Pronunciamento Conceitual Básico: Estrutura Conceitual para a Elaboração e Apresentação das Demonstrações Contábeis. $\quad$ Brasília, 2008. Disponível em: $\left\langle\right.$ http://www.cpc.org.br/pdf/pronunciamento_conceitual.pdf $>$. Acesso em: $1^{\circ}$ jun. 2011, 17:36:15.

COPELAND, T.; KOLlER, T.; MURRIN, J. Avaliação de Empresas - Valuation: Calculando e gerenciando o valor das empresas. McKinsey \& Company, Inc. 3. ed. São Paulo: Pearson Makron Books, 2002.

DAMODARAN, A. Avaliação de Investimentos: ferramentas e técnicas para a determinação do valor de qualquer ativo. Rio de Janeiro: Qualitymark, 1997.

DIMITROPOULOS, P. E.; ASTERIOU, D. The value relevance of financial statements and their impact on stock prices: evidence from Greece. Managerial Auditing Journal, v. 24, n. 3, p. 248-265, 2009.

EBAID, I.E. The value relevance of accounting-based performance measures in emerging economies: The case of Egypt. Management Research Review, v. 35, n.1, p.69-88, 2011.

FADER, P.S.; HARDIE, B.G.S. Customer-base valuation in a contractual setting: The perils of ignoring heterogeneity. Marketing Science, v. 29, n. 1, p. 85-93, 2010.

FIORDELISI, F.; MOLYNEUX, P. The determinants of shareholder value in European banking. Journal of Banking and Finance, v. 34, p. 1189-1200, 2010.

FREZATTI, F. Gestão de Valor na Empresa: Uma Abordagem Abrangente do Valuation a partir da Contabilidade Gerencial. São Paulo: Atlas, 2003.

GRANT, J.L. Foundations of Economic Value Added. 2. ed. New Jersey: John Wiley \& Sons, 2003.

HAIR JR., J.F.; ANDERSON, R.E.; TATHAM, R.L; BLACK, W.C. Análise Multivariada de Dados. 5 ed. Porto Alegre: Bookman, 2005.

HALL, J.H. Correlating internal and external performance yardstickis in the evaluation of corporate wealth creation. Meditari Accountancy Research, n. 7, p. 123-143, 1999.

HAMADA, R.S. Portfolio analysis market equilibrium and corporate finance. The Journal of Finance, v. 24, n. 1, p. 13-31, 1969.

HELOU NETTO, F.; PEREIRA, C. C. Impacto da republicação de demonstrações financeiras no preço das ações de empresas brasileiras. Revista Contemporânea de Contabilidade, UFSC, Florianópolis, ano.7, v.7, n.14, p. 29-50, jul./dez. 2010.

IPEADATA. EMBI+ Risco Brasil: JP Morgan, frequência diária, 2011a. Disponível em: <www.ipeadata.gov.br>. Acesso em: 15 maio 2011.

IPEADATA. Taxa de Juros: bônus governamental dos Estados Unidos - maturidade 10 anos, periodicidade mensal (\% a.a.), 2011b. Disponível em: 〈www.ipeadata.gov.br $\rangle$. Acesso em: 15 maio 2011. 
JACQUES, F. V. S.; RASIA, K. A.; QUINTANA, A. C.; QUINTANA, C. G. Contabilidade e a sua relevância nas boas práticas de Governança Corporativa. Revista Contemporânea de Contabilidade, UFSC, Florianópolis, ano.8, v. 8, n.16, p. 37-64, jul./dez. 2011.

JORION, P. Financial Risk Manager Handbook. 2. ed. New Jersey: John Wiley \& Sons, 2003.

JOSHI, A.; HANSSENS, D. M. The direct and indirect effects of advertising spending on firm value. Journal of Marketing, v. 74, n. 1, p. 20-33, 2010.

KLEINBAUM, D.G. Logistic Regression: a self-learning text. New York: Springer, 1996.

KOLLER, T. What is value-based management? In: T. Copeland, T. Koller, \& J. Murrin. Valuation: Measuring and Managing the Value of Companies (2. ed., p. 87-101). New York: McKinsey \& Company, 1994.

KOLLER, T.; GOEDHART, M.; WESSELS, D. Valuation: Measuring and Managing the Value of Companies. 4. ed. New Jersey: McKinsey \& Company, 2005.

KOTHARI, S. P. Capital Markets research in accounting. Journal of Accounting and Economics, v. 31, p. 105-231, 2001.

LINTNER, J. The Valuation of Risk Assets and the Selection of Risky Investments in Stock Portfolios and Capital Budgets. The Review of Economics and Statistics, v. 47, n. 1, p. 1337, 1965.

MAGNI, C. A. Economic profit, NPV, and CAPM: Biases and violations of Modigliani and Miller's Proposition I. MPRA Paper, n. 11399, 2005. Disponível em: <http://mpra.ub.unimuenchen.de/11399/>. Acesso em: $1^{\circ}$ jun. 2011, 17:15:30.

MARTIN, J. D.; PETTY, J. W. Gestão Baseada em Valor: uma resposta das empresas à revolução dos acionistas. Qualitymark: Rio de Janeiro, 2004.

MARTINS, E. (Org.). Avaliação de Empresas: Da Mensuração Contábil à Econômica. 1. ed. São Paulo: Atlas, 2009.

MATARAZZO, D. C. Análise Financeira de Balanços: Abordagem Básica e Gerencial. 6. ed. São Paulo: Atlas, 2003.

MODIGLIANI, F.; MILLER, M. H. The Cost of Capital, Corporate Finance and the Theory of Investment. The American Economic Review, v. 48, n. 3, p. 261-297, 1958.

MOSKOWITZ, J. What is your business Worth? Management Accounting, n. 66, p. 30-34, 1988.

MURCIA, F. D.; SILVA, A. C.; BARRETO, E.; CARVALHO, L. N. G. Conjectures Regarding the Adoption of Fair Value Measurements in Brazil. Revista Contemporânea de Contabilidade, UFSC, Florianópolis, ano 5, v. 1, n.9, p. 11-28, jan./jun. 2008.

OHLSON, J. A. Earnings, book value and dividends in equity valuation. Contemporary Accounting Research, v. 11, n. 2, p. 661-687, 1995.

PALMA, M. A. M. A capacidade de inovação como formadora de valor: análise dos vetores de valor em empresas brasileiras de biotecnologia. 2004. 175 f. Tese de Doutorado, 
Faculdade de Administração, Economia e Contabilidade da Universidade de São Paulo, São Paulo, 2004.

PENHA, R. N. Um Estudo sobre Regressão Logística Binária. 2002. 10 f. Trabalho de Formatura, Universidade Federal de Itajubá, Instituto de Engenharia Mecânica, Departamento de Produção, 2002.

PEREIRA, V. L.; SANTANA, A. C.; MENDES, F. A. T.; KHAN, A. S. Análise do setor de energia elétrica do estado do Pará: uma aplicação da matriz de insumo-produto. Amazônia: Ciência \& Desenvolvimento, Belém, v. 4, n. 7, p. 7-26, jul./dez. 2008.

PESTANA, M.H.; GAGEIRO, J.N. Análise de Dados para Ciências Sociais - A Complementaridade do SPSS. 3. ed. Lisboa: Edições Sílabo, 2003.

PIGNANELLI, A. Qualidade x Desempenho: Mito ou Realidade? 2007. 131 p. Dissertação de Mestrado em Administração de Empresas, Escola de Administração de Empresas de São Paulo da Fundação Getúlio Vargas, São Paulo, 2007.

PORTERFIELD, J. T. S. Decisões de Investimento e Custo de Capital. São Paulo: Atlas, 1976.

RAPPAPORT, A. Gerando valor para o Acionista: um guia para administradores e investidores. São Paulo: Atlas, 2001.

REFAEILZADEH, P.; TANG, L.; LIU, H. Cross Validation. In: Encyclopedia of Database Systems, Editors: M. Tamer Özsu and Ling Liu. Springer, 2009.

SAMI, H.; ZHOU, H. A comparison of value relevance of accounting information in different segments of the Chinese stock market. International Journal of Accounting, v. 39, n. 4, p. 403-427, 2004.

SERRATO, E. Fronteiras paramétricas de eficiência para o segmento de transmissão de energia elétrica no Brasil. 2006. 79 f. Dissertação (Mestrado em Economia do Setor Público) - Faculdade de Economia, Administração, Contabilidade, Ciência da Informação e Documentação, Universidade de Brasília, Brasília, 2006.

SHARPE, W. F. A Theory of Market Equilibrium under Conditions of Risk. The Journal of Finance, v. 19, n. 3, p. 425-442, 1964.

SILVA, W. A. C. Investimento, regulação e mercado: Uma análise do risco no setor elétrico. 2007. 451 f. Tese (Doutorado em Administração) - Universidade Federal de Lavras, Lavras, 2007.

SOBUE, M. A.; PIMENTA JR., T. A Relação entre a Geração de Valor Econômico e o Valor de Mercado das Empresas Sucroalcooleiras Brasileiras. Revista Contemporânea de Contabilidade, UFSC, Florianópolis, v. 9, n.17, p. 103-120, jan./jun. 2012.

SONG, C. J.; THOMAS, W. B.; YI, H. Value relevance of FAS No. 157 Fair Value hierarchy information and the impact of corporate governance mechanisms. Accounting Review, v. 85, n. 4, p. 1375-1410, 2010.

SRINIVASAN, P.; NARASIMHAN, M. S. The value relevance of consolidated financial statements in an emerging market: The case of India. Asian Review of Accounting, v.20, n.1, p.58-73, 2012. 
STEVENSON, W. J. Estatística aplicada à administração. São Paulo: Harper \& Row do Brasil, 1981.

STEWART, G. B. The quest for value: The EVA management guide. USA: HapperCollins, 1991.

TAVARES FILHO, F. Rentabilidade e valor das companhias no Brasil: Uma análise comparativa das empresas que aderiram aos níveis de governança corporativa da Bovespa. 2006. 160 p. Dissertação de Mestrado em Ciências Contábeis, Faculdade de Economia, Administração e Contabilidade da Universidade de São Paulo, São Paulo, 2006.

TRÉMOLIÈRES, R.; TURKO, A. Valuation of internet firms in mergers \& acquisitions. Journal of Internet Banking and Commerce, v. 14, n. 3, p. 1-9, 2009.

TSALAVOUTAS, I.; ANDRÉ, P.; EVANS, L. The transition to IFRS and the value relevance of financial statements in Greece. The British Accounting Review, v. 44, p. 262-277, 2012.

YAHOO FINANCE. NYSE Composite Index: historical prices, montly, adjusted close, 2011. Disponível em: 〈http://finance.yahoo.com> Acesso em: 15 maio 2011.

YOUNG, S. D.; O’BYRNE, S. F. EVA e Gestão Baseada em Valor: Guia prático para implementação. Porto Alegre: Bookman, 2003. 